\title{
Pilot health project baseline survey West Bank and Gaza [Arabic]
}

Frontiers in Reproductive Health

Follow this and additional works at: https://knowledgecommons.popcouncil.org/departments_sbsr-rh How does access to this work benefit you? Let us know!

\section{Recommended Citation}

"Pilot health project baseline survey West Bank and Gaza [Arabic]," Summary of Key Findings. Cairo: Population Council, 2001. 


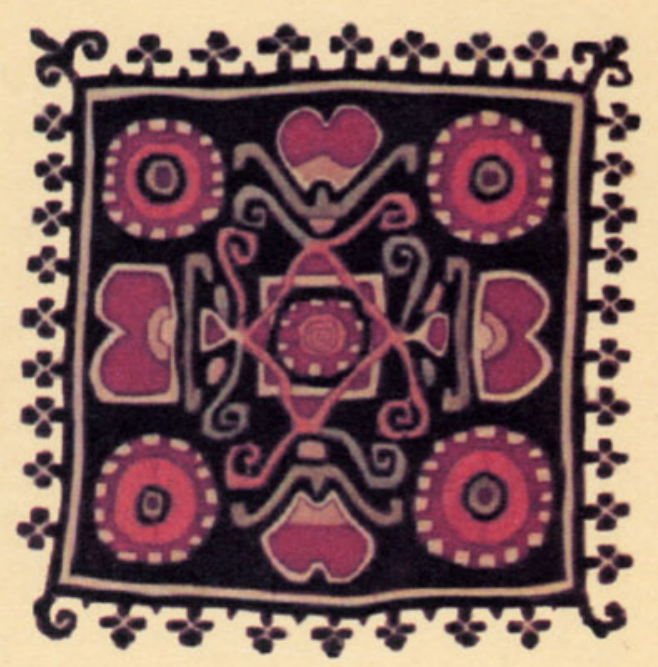

\section{المسح الأساسي للمشروع الصحي التبريبي

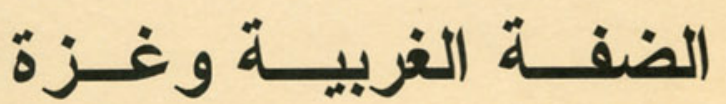

$$
\text { ملخص لنتائج الار اسة }
$$




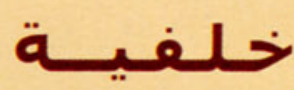

يشكل نقص الرعاية الصحية للمر أة وللأطفال حديثي الو لادة خلال فترة ما بعد الو لادة فجوة خطيرة في نظام الرعاية الصحية الأولية بالضفة الغربية وغزه. فبالرغم من أن نسبة كبيرة من النساء يتلقين بعض الرعاية الصحية أثناء فترة الحمل، إلا أن عددا قليلا جدا منهن يعدن مرة أخرى إلى عيادات الرعاية الصحية لعمل زيار ات متابعة ما بعد الو لادة ، حيث أن نسبة VIV\% فقط من النساء يعدن لإجر اء الفحوصات الطبية الخاصة بفترة ما بعد الو لادة كما أن القليل منهن يستخدمن وسائل تتظيم الأسرة للمباعدة بين الولادات خلال الفترة

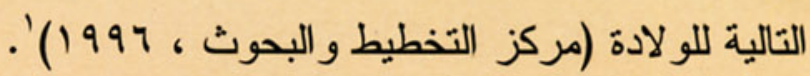

وتعتبر معدلات الخصوبة في كل من الضفة الغربية وغزه مرتفعة بالمقارنة بالبلدان الأخرى بالمنطقة والتي تتميز بمستوى تتمية مماثل حيث أن منوسط عدد الأطفال للنساء المتزوجات اللاتي في سن الإنجاب في غزه منه

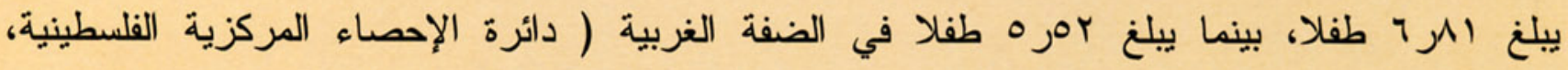

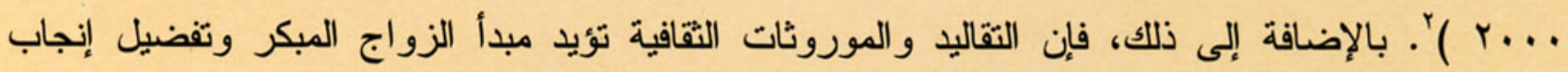
الذكور وتكوين أسر كبيرة العدد. وبما أن حوالي نصف سكان الضفة الغربية وغزة تقريبا (ور ؟ـ\%) تقل أعمار هم عن 10 عاما ، فإنه من المنتظر أن نكون هناك زيادة كبيرة في عدد السكان حتى وان انخفضت معدلات المواليد خلا السنوات المقبلة (وزارة الصحة الفلسطينية، 1991، دائرة الإحصاء المركزية

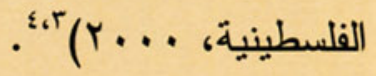

وفي إطار الجهود المبذولة لتحسين وتطوير صحة المرأة والطفل الفلسطيني في الضفة الغربية وغزه، قامت الوكالة الأمريكية للتمية الدولية (USAID) بالتعاون مع وزارة الصحة الفلسطينية وسبع شركاء آخرين بالاشتر الك في تصميم وتمويل المشروع الصحى التجريبى الذى يجرى تتفيذه على مدى ب شهرا فى الضفة

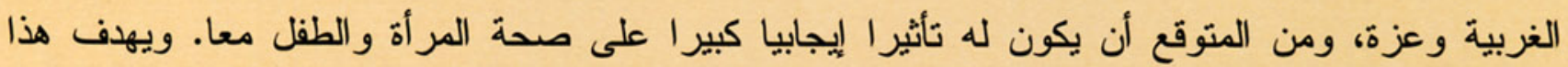
المشروع إلى تطوير الخدمات الصحية أثناء فترة الحمل وبعد الو لادة في YV عيادة تقدم خذمات صحية أولية في ثلاث مناطق بالضفة الغربية وغزه. وتشمل تداخلات المشروع إنشاء مجموعة أساسية من الخدمات عالية

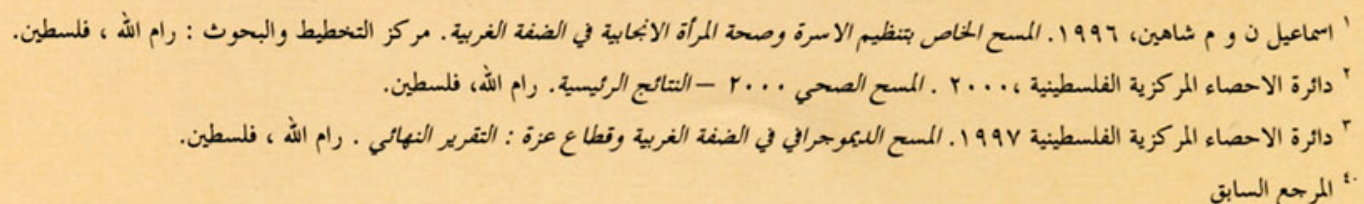

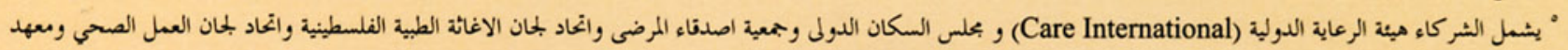
الاعلام والسباسات الصحية والثنموية ومركز تنمية الرعاية الصحية الاولية. 
المسنوى للرعاية الصحية أثناء فترة الحمل وبعد الو لادة، وذلك بهدف تحسين أساليب تقديم الخدمات الصحية

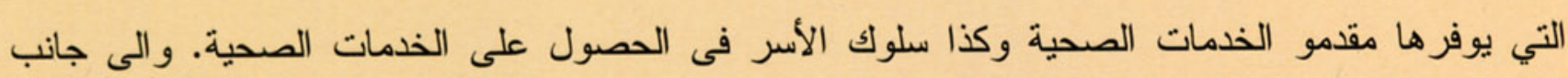
ذلك، فسوف يساهم المشروع في نوفير بيانات دقيقة وموثوق بها عن الصحة الإنجابية بما في ذلك صحة الأم و الطفل وتتظيم الأسرة وذلك على مستوى الرعاية الصحية الأولية. و من اجل قياس مستوى المؤشرات

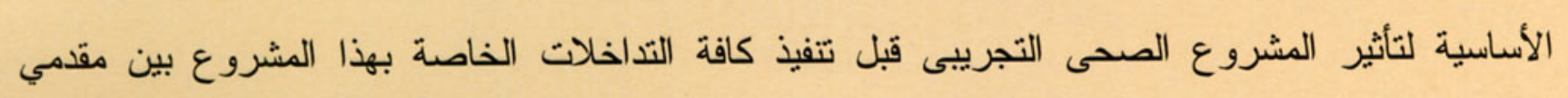

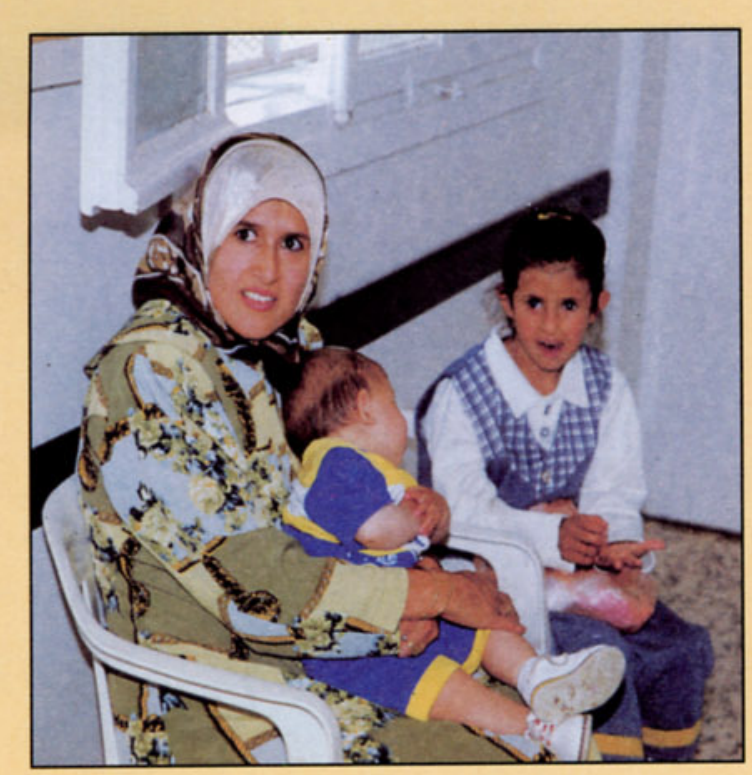
الرعاية الصحية ومتلقي هذه الخدمات ، فقد تم القيام بمسح

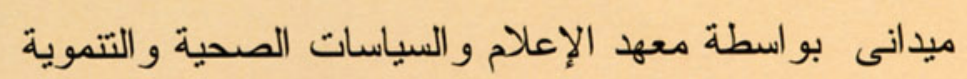

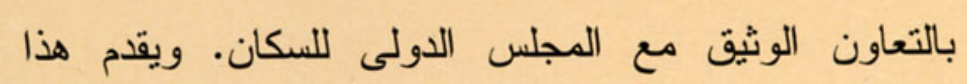

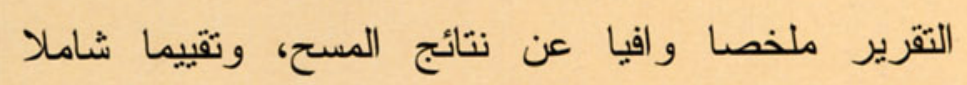
لخدمات الرعاية الصحية أثناء الحمل وبعد الولادة وخدمات

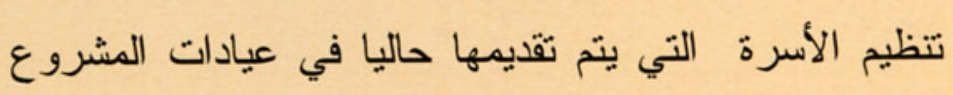
(قبل القيام بأية تداخلات للمشروع).

\section{هـدف الدراســة ومؤشـراتـها}

إن الهدف الرئيسي من إجراء هذه الدراسة هو تحديد مستوى المؤشرات الأساسية لمخرجات المشروع

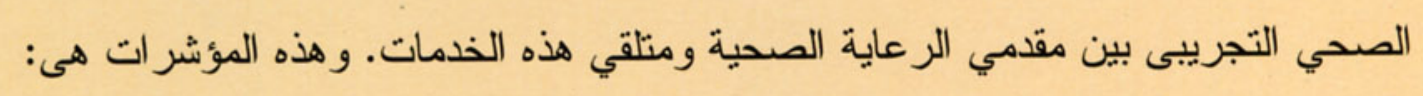

المؤشر الأول: نسبة الأمهات والأطفال الرضع الذين عادوا لزيارة العيادات بغرض الحصول على خدمة الرعاية الصحية بعد الو لادة وذللك من بين النساء اللاتي حصلن على رعاية صحية أثثاء فترة الحمل (ويشمل

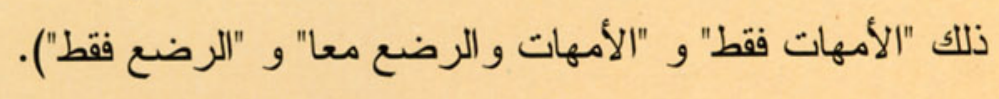

المؤشر الثاني: نسبة الأمهات اللاتي يقبلن استخدام وسائل تتظيم الأسرة من بين الأمهات اللاتي عدن لعمل زيار ات متابعة بعد الو لادة.

المؤشر الثالث: نسبة النساء اللاتي لديهن عدد قليل من الأطفال (طفل أو اثثين أحباء) ويقبلن استخدام إحدى وسائل تنظيم الأسرة.

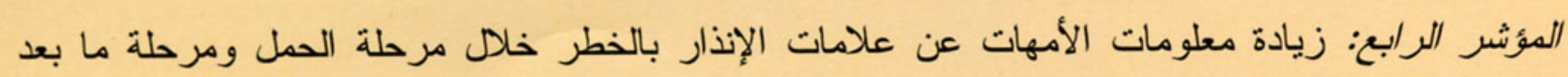
الو لادة بالنسبة لأنفسهن و أطفالهن الرضع. 
المؤشر الخامس: زيادة نسبة النساء اللاتي يسعين إلى العلاج في حالة إكتشافهن علامات الإنذار بالخطر لديهن أو لدى أطفالهن. المؤشر السادس: زيادة معلومات النساء وممارسة الفحص الذاتى للثدى و إختبار مسحة عنق الرحم. المؤشر السابع: زيادة نسبة الأزواج و الرجال الذين لديهم وعي خاص بأهمية المباعدة بين الولادات بفترة لا

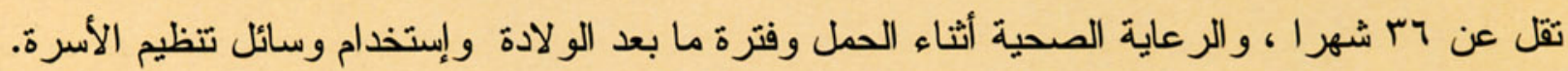
المؤشر الثامن: زيادة المعلومات و المهار ات لدى جميع فئات مقدمى الذدمة الصحية المؤشر التاسع: تزويد النساء الحوامل والنساء خلال فترة النفاس بمعلومات عن التغذية والنظافة والرضاعة

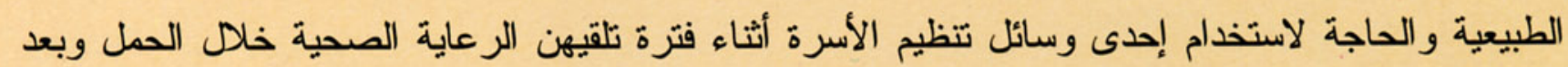
الو لادة.

كما سيتم إجراء مسح بعدي يهدف إلى جمع بيانات مماتلة عن المؤشرات الأساسية لمخرجات المشروع وذلك بعد الانتهاء من تتفيذ كافة تداخلات المشروع الصحي التجريبى.

\section{فـروض الدراســـة}

بالرغم من اقتصار هذا التقرير على المسح الميدانى الذى تم القيام به قبل تتفيذ تداخلات المشروع، فإن المسح

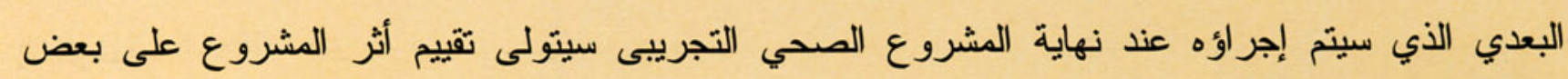
المؤشرات المختارة. لذا، فإن الفروض التالية تتعلق بتصميم الدراسة بكافة مر احلها (أي قبل وبعد التداخلات

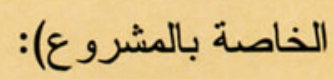

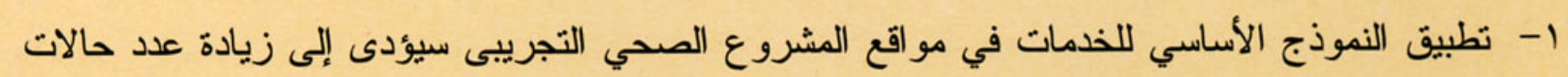

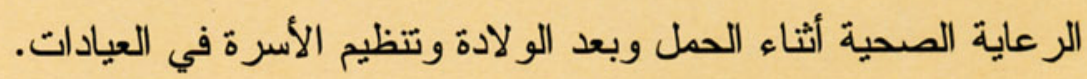

r- سوف تتحسن مهارات وممارسات مقدمي الذدمة الصحية الذين يتلقون التذريب ويقدمون الذدمات في

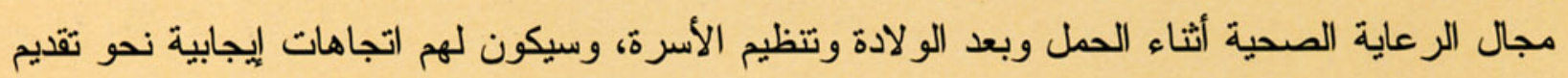
خدمات منكاملة. 
r- - النساء اللاتي تتلقين الخدمة الصحية (وعائلاتهن) سوف يصبح لديهن معرفة أكثر وقبول أكبر

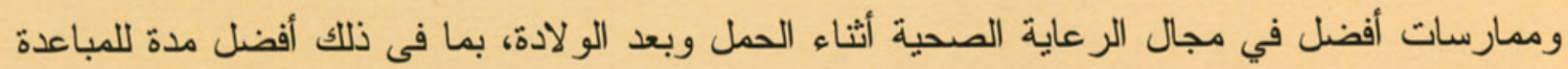
بين الو لادات و استخدام وسائل تنظيم الأسرة.

\section{منـــــ البـحــث}

استخدمت الدراسة أساليب متعددة في جمع البيانات للحصول على التقديرات الكمية الضرورية للمؤشرات الرئيسية. وقد تم تطبيق مناهج البحث الثلاثة التالية: إستخلاص بعض احصاءات الخدمة التى يتم جمعها بشكل روتينى، و إجر اء مقابلات مع مقدمي الخدمات الصحية، وكذلك إجر اء مقابلات مع النساء اللاتى حصلن على لـى خدمات الرعاية الصحبة أثثاء الحمل وبعد الو لادة وتتظيم الأسرة وذلك بعد الحصول على الخدمة وقبل مغادرة

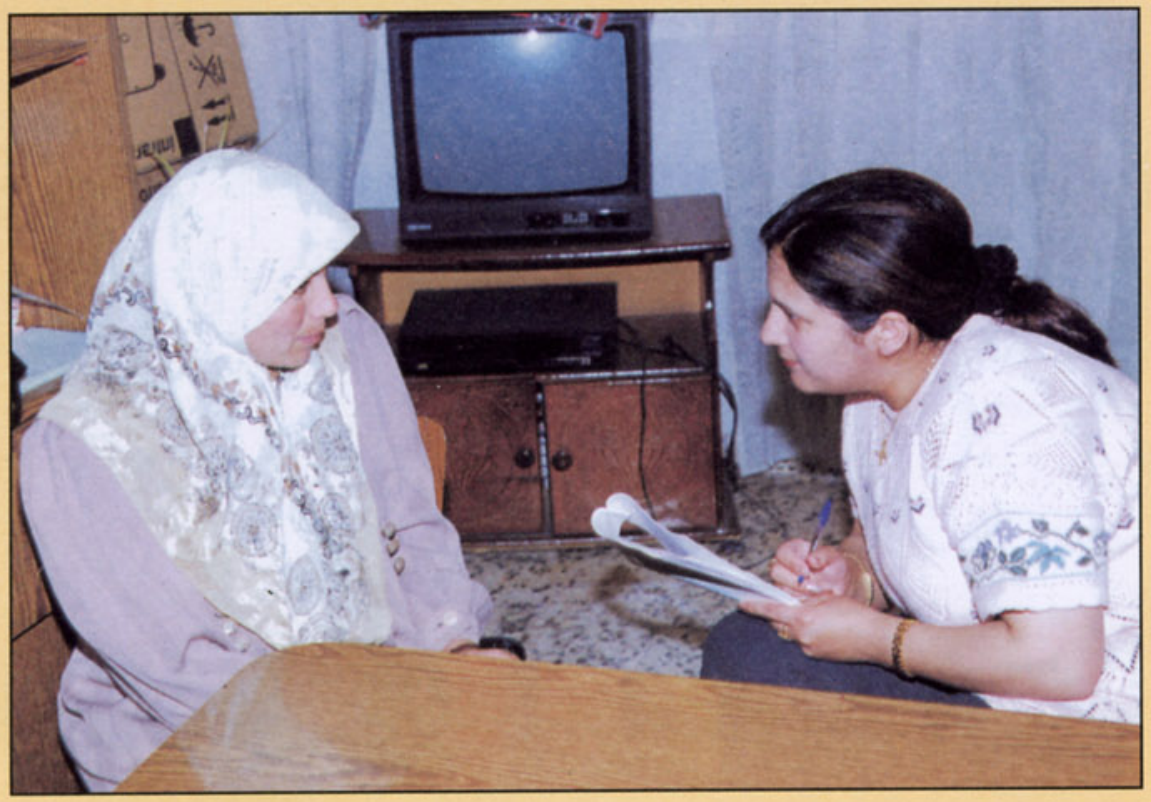

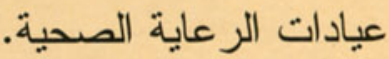

وينكون إطار عينة الدراسة من rV عيادة شملها المشروع الصحي التجريبى ونقع هذه العيادات في القرى المحيطة بمنطقة جنين، و الخليل وغزه، وهى عيادات تتولى إدارتها الجمعيات الأهلية غير الحكومية الثلاثة المشاركة في الحئ المشروع وهى إتحاد لجان الإغائة الطبية الفلسطينية (UPMRC) وجمعية أصدقاء المرضى (PFS) و إتحاد لجان العمل الصحي (UHWC). ولغرض الدراسة، تم إجر اء مقابلات مع تسعة أطباء وثلاث ممرضات واثثين وأربعين عاملة صحية كانوا يعملون في عيادات المشروع الصحي التجريبى. كما أجريت مقابلات مع جميع متلقيات الخدمة الصحية أثناء الحمل وبعد الو لادة وكذا خدمات تنظيم الأسرة ممن قمن بزيارة العيادات أثناء فترة جمع البيانات. ولم يتم إدراج متلقيات الخدمة اللاتي زرن العيادات لغرض الحصول على خدمات صحية إنجابية أخرى أو خدمات رعاية صحية أولية في الدراسة. وقد استهدفت هذه الدراسة جمع عينة مكونة من باع مقابلة مع النساء متلقيات الخدمات وذللك بعد الانتهاء من الحصول على الخدمة وقبل مغادرة العيادات (إجمالي حجم العينة المستهدف . . . (). ومع ذلك، فقد كانت هناك معوقات عديدة حالت دون تحقيق حجم العينة المستهدف في جميع العيادات. وقد تمثلت هذه العو ائق بصفة أساسية فى كثرة تتقل الأطباء بين العيادات وقلة عدد الحالات. 
ونتيجة لذللك، فقد قامت الدراسة بأخذ عينات اكبر مما هو مقرر في العيادات التي تتميز بارتفاع عدد الحالات. كما تم مد إجر اءات جمع البيانات لأسبوعين آخرين عما كان مقررا وعلى هذا، فقد بلغ إجمالي حجم العينة V9r متلقية للخدمات.

ومن الجدير بالذكر أن القائمين بإجر اء المقابلات والمشرفين الميدانيين شاركوا في دورة تدريبية مكثفة حول

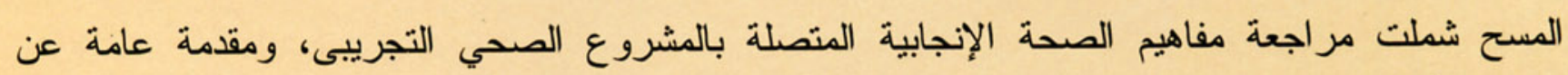
المسوح الميدانية، وتعريف المقابلات النمطية وخصائصها ، ومناقشة الخطوات التالية لمرحلة جمع البيانات (الترميز، وتجهيز البيانات آليا). كما نم شرح أقسام الاستبيان المخصص لإجر اء المقابلات مع متلقيات الذدمة

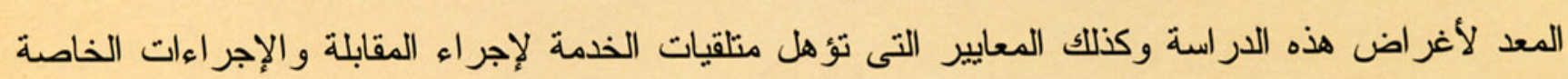
بأخلاقيات الحصول على مو افقتهن لإجر اء المقابلة.

وقد تم عمل إختبار قبلى للإستبيان المخصص لإجر اء المقابلات مع متلقيات الخدمة في اربع عيادات مختلفة غير مدرجة في المشروع الصحي التجريبى (بدو، قلقيليه، طولكرم وغزه). وقد تم جمع البيانات فيى عبادات

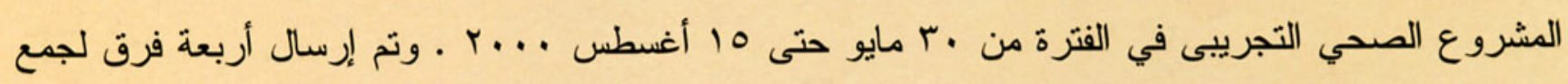

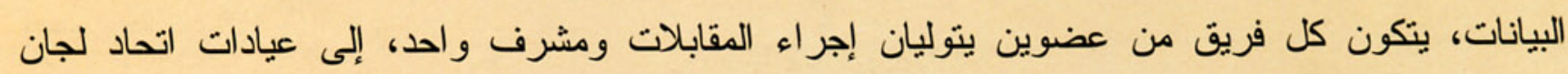
الإغاثة الطبية الفلسطينية (UPMC) وجمعية أصدقاء المرضى (PFS) و إتحاد لجان العمل الصحي (UHWC)

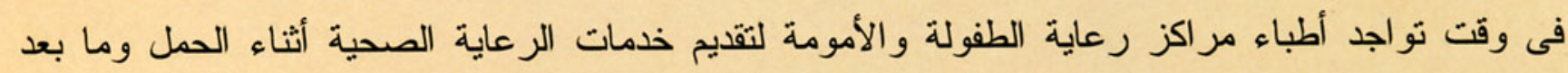

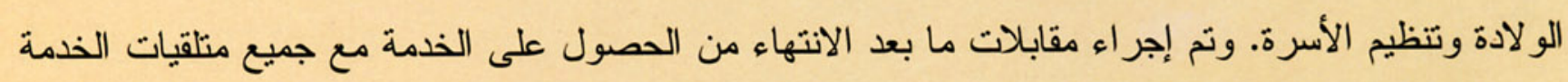

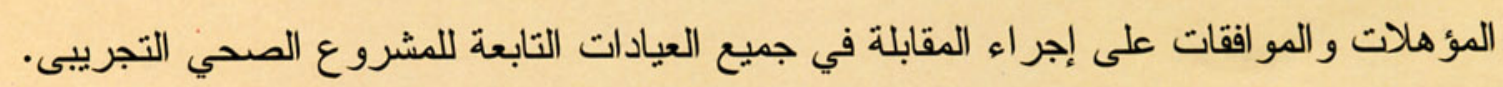

وقد تم أيضا إجراء مقابلات مع أطباء مراكز رعاية الأمومة والطفولة وممرضات العيادات والعاملات

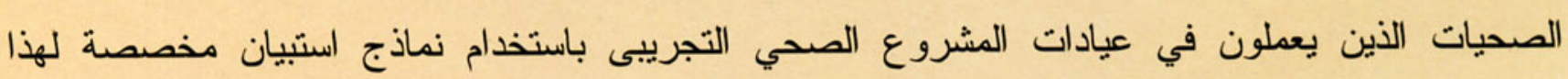
الغرض. وقد نم القيام بهذه المقابلات بو اسطة مشرفي جمع البيانات الذين يتمتعون جميعا بخبرة مكثفة في بئي المجال الصحي أو في الأبحاث الصحية.

وتم استخلاص إحصاءات الخدمة عن الحالات طبقا لسبب الزيارة خلال الفترة من نوفمبر 1999 حنى مايو

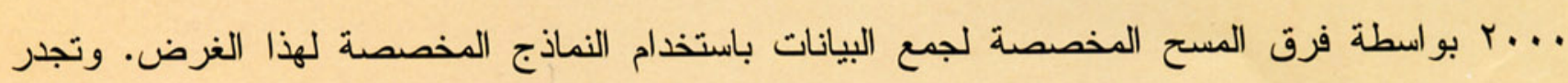
الإشارة إلى أن إحصاءات الخدمة التى يتم جمعها بطريقة روتينية ليست مسجلة بطريقة منظمة فى عيادات 
المشروع الصحى التجريبى وحتى فى الحالات التى كانت فيها هذه الإحصاءات منوفرة كانت البيانات ناقصة وغير مكتملة. ومن المنتظر أن يعالج المشروع الصحي التجريبى هذا القصور بإنشاء نظام شامل للمعلومات.

\section{نتـائسج الـدراســـة}

بعض الخصائص المختارة للسبي/ت اللاحى حصلن على الخدمات

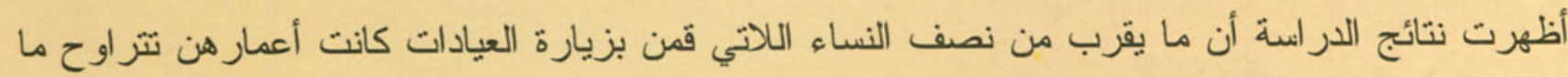

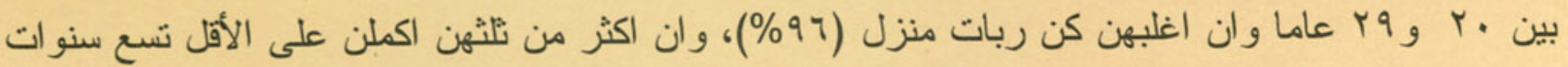

اكثر من نصف السيدات اللاتى قمن بزيارة العيادات

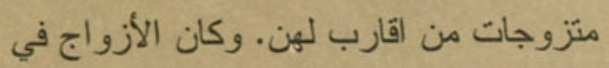

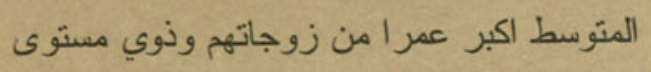

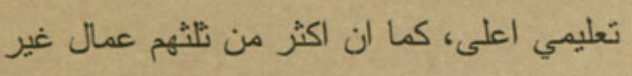
مهرة.
من الدراسة. وقد أشارت الدراسة إلى أن المرأة الفلسطينية

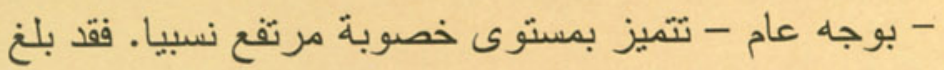
منوسط عدد المواليد الأحياء بالنسبة للنساء اللاتي قمن فرك بزيارة عيادات المشروع الصحي التجريبى ثلاثة مو اليد. كما

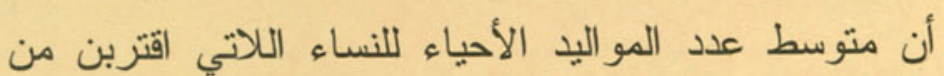
نهاية سن الانجاب (•ع عاما أو اكثر) بلغ اكثر من V مو اليد. وقد صرح هؤلاء النسوة بأن أزو اجهن بفضلون

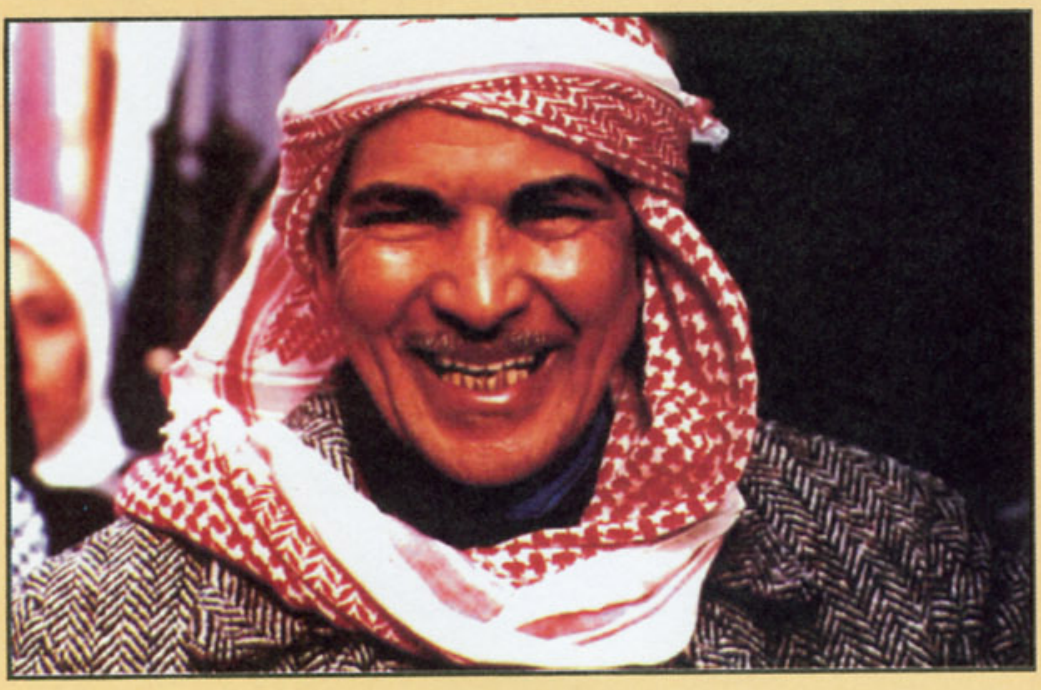

نسب خصوبة أعلي بالمقارنة بأنفسهن. كما أفادت .0\% بر غبتهن في إنجاب مزيد بان بان من الأطفال بالمقارنة بنسبة بvo\% بين

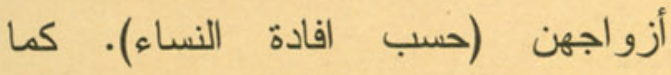
صرحن بأن أزواجهن يفضلون إنجاب الذكور بصورة اكبر بالمقارنة بأنفسهن.

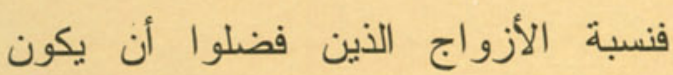
المولود القادم ذكر ا بلغت بr\% بالمقارنة

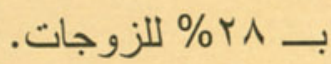

بعض الخصائص المختارة لمقدمي الخدمة يقوم تسعة أطباء و ثلاث ممرضات و اثثين و اربعين عاملة صحية بتقديم خدمات فى عبادات المشروع الصحي

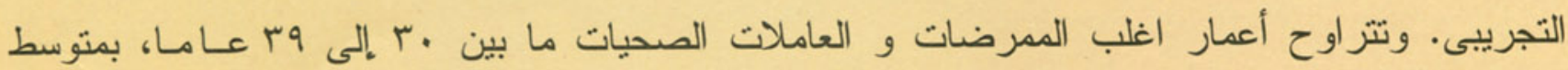
عمري يبلغ ^ر عَ عاما. كما ان ما يقرب من ثلاثة أخماس الممرضات و العاملات الصحيات حاصلات على بنى 
دبلومات قد تختلف حسب المنظمات غير الحكومية التى يعملن بها (جميع الممرضات حاصلات على دبلوم). وغالبا ما نكون العاملات الصحيات لدى جمعية أصدقاء المرضى حاصلات على شهادة دبلوم تفيد بتلقيهن تدريبا مدته عامين من مركز التتمية فى الرعاية الصحية الأولية. أما العاملات الصحيات لدى اتحاد لجان العمل الصحي فهن غير حاصلات على دبلوم ولكن لديهن شهادات تفيد بحصولهن على تدريب مدته ؛ إلى 7 اشهر في مجال صحة المجتمع. ومن المهم ملاحظة ان ما يقرب من خمسي العاملات الصحيات ليس لديهن أي نوع من أنواع التعليم. كما أن الممرضات و العاملات الصحيات عملن في المتوسط- لمدة خمس سنوات في العيادات التي تم فيها إجر اء المقابلة معهن. ووفقا لنوع المنظمة غير الحكومية اللاتي يعملن بها، فإن اغلب

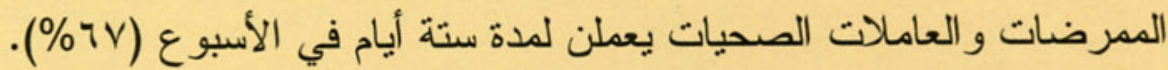

وقد أشارت نتائج الدراسة إلى أن بعض الأطباء يشكلون جزءا من الفريق الطبى المتتقل الذى يقوم بزيارة

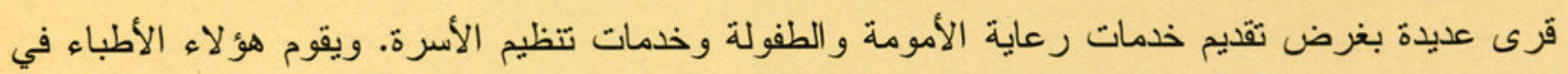
بعض الأحيان بزيارة عدة عيادات في اليوم الواحد. وقد أثارت الدراسة إلى أن عمر الأطباء في المتوسط اصغر قليلا من عمر الممرضات والعاملات الصحيات (المتوسط العمري ار بس عاما) وقد التحقو ا بالهيئات غير الحكومية المختلفة في تواريخ حديثة نسبيا عن تواريخ التحاق الممرضات و العاملات الصحيات بالعمل باتل

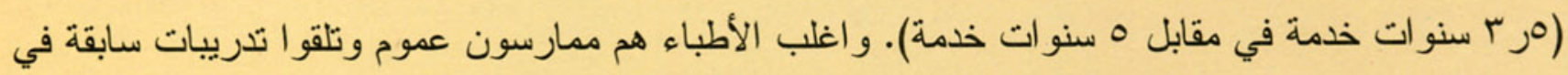

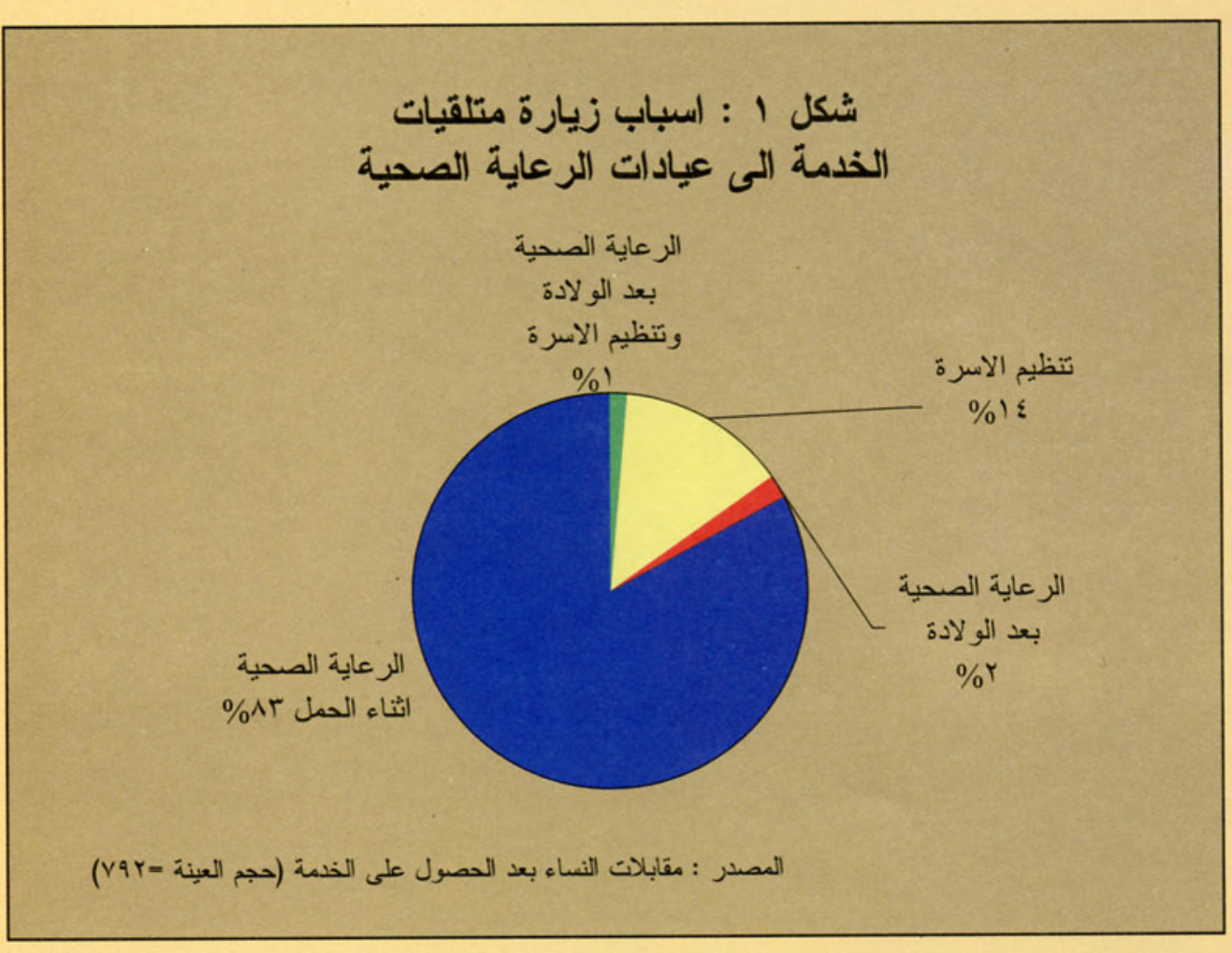

مجال صحة المرأة، إلا أن اغلبهم صرحوا برغبتهم في الحصول على مزيد من التنريب الإضافي لنطوير مهار اتهم في مجال الرعاية الصحية للمر أة.

\section{إحصاءات الخدمة}

حاولت الدر اسة استخلاص إحصاءات الخدمة المجمعة بطريقة روتينية خلا فترة الأشهر الستة السابقة على إجر اء المسح القبلى وفقا لسبب الزيارة ، وأسفرت المحاولة عن نتائج مختلطة وضعيفة المستوى بوجه 
عام (أي ناقصة ولا يمكن الوثوت بها). كما أشارت هذه الإحصاءات إلى عدم تو افر خدمة ما بعد الولادة في العيادات في اغلب الأحيان، على الرغم ما يبدو من نو اجد الأنشطة الميدانية للعاملات الصحيات خلال فترة ما بعد الو لادة. وبالمقارنة، فقد وجدت الدر اسة ان خدمة الرعاية الصحية أثثاء الحمل تبدو متوطدة بصورة اكبر. تتفق هذه النتائج بصورة جيدة مع بيانات المسوح و الدر اسات السابقة التي تم إجر اؤها في هذا الصدد. ويوضح الثكل رقم (1) أن اغلب الزيارات التى تمث فى العيادات المشاركة في الدراسة كانت لغرض الحصول على خدمة الرعاية الصحية أثناء الحمل (r^\%). أما السبب الثاني الأكثر شيوعا لزيارة العيادات فقد كان لغرض الحصول على خدمات تتظيم الأسرة (ع (\%). وقد أفادت نسبة قليلة فقط من النساء بان سبب الزيارة هو الحصول على الرعاية الصحية لفترة ما بعد الولادة (ب\%).

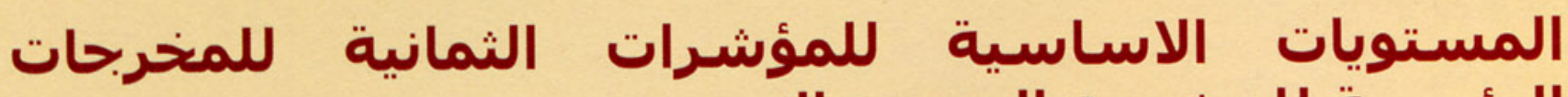

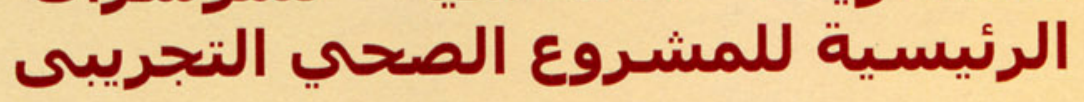

المؤثر الأول : نسبة الأمهات والأطفال الرضع الذبن عادوا لزيارة العيادات بغرض العصول على الرعاية

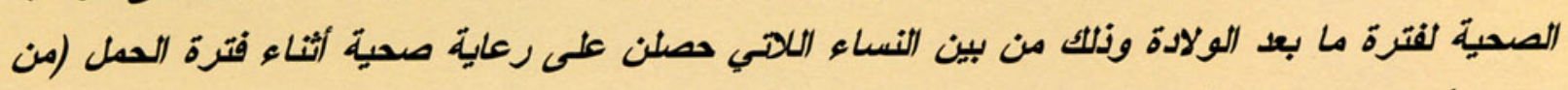

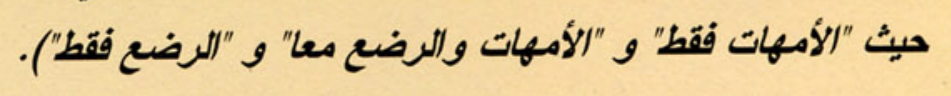

بلغ عدد زيار ات النساء الحوامل إلى العيادات للحصول على الرعاية الصحية أثناء الحمل ه زيارات في المتوسط وقد اهتمت الكثير من هؤلاء النسوة بالحصول على الرعاية الصحية في وقت مبكر من تاريخ الحمل وتحديدا خلا الأشهر الخمسة الأولى من الحمل. ومع ذلك، فإن نسبة rرب\% فقط من النساء اللاتي تمت مقابلتهن (Vr سيدة) أفدن بعودتهن إلى العيادة مرة أخرى للحصول على الرعاية الصحية لفترة ما بعد الو لادة.

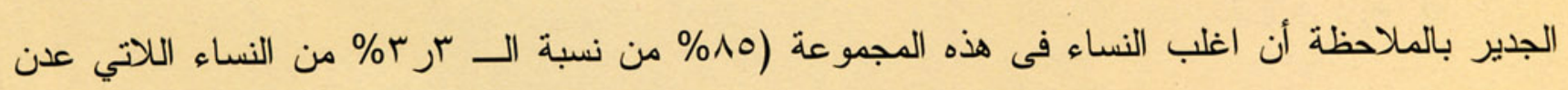
للحصول على الخدمة الصحية لفترة ما بعد الولادة) وضعن أطفالهن في المسنشفى. و اغلب النساء اللاتي عدن في زيارات ما بعد الولادة أثين للزيارة قبل انقضاء أربعين يوما على تاريخ الولادة (ع^\% من نسبة الـ سر با اللاتي عدن للحصول على الرعاية الصحية بعد الولادة). ومع ذلك، فعندما سئلن عن عدد

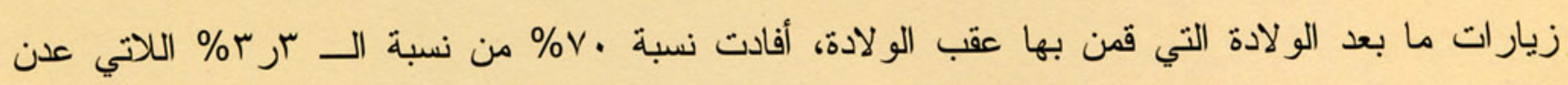
للحصول على رعاية ما بعد الولادة بأنهن زرن العيادة لمرة واحدة فقط بعد الولادة. كما أن نسبة كبيرة من النساء اللاتي سعين للحصول على خدمة ما بعد الولادة ، سبق لهن تلقي خدمة الرعاية الصحية أثثاء الحمل

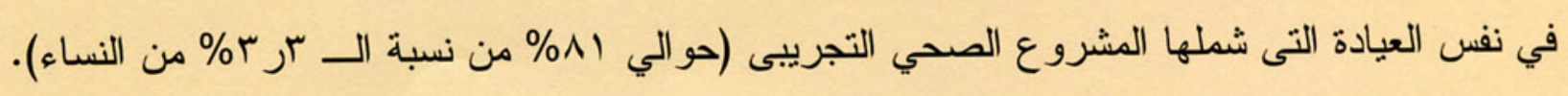




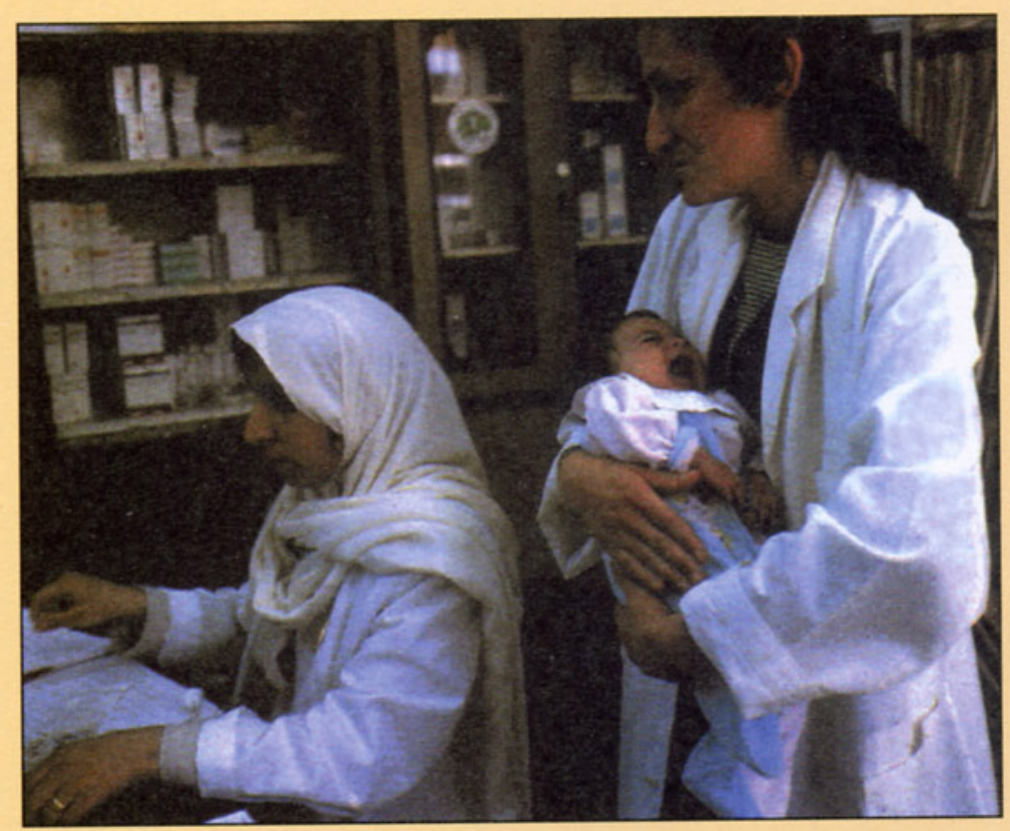

وقد ذكر ما يقرب من نصف عدد النساء السبعة و العشرين اللاتي تلقين خدمة ما بعد الو لادة بأنهن زرن العيادات لتلقي رعاية ما لانئ

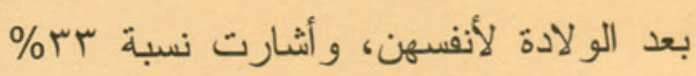
إلى أنهن طلبن خدمات رعاية صحية لأنفسهن و لأطفالهن الرضع. وقد تضند أسباب الزيارة للحصول على رعاية ما بعد ولعد ولئ الو لادة لأنفسهن: الفحص الطبي بعد الو لادة وطلب الرعاية الطبية لمشكلة صحية وطلب النصيحة أو اسنشارة بشأن وسائل تنظيم الآسرة أو الحصول على وسيلة تنظيم الأسرة. أما النساء اللاتي قمن بزيارات ما بعد الولادة لغرض إجر اء فحوص طبية لأطفالهن الرضع فقد كانت لغرض الاطمئنان على صحة أطفالهن أو الحصول على اسنثارات طبية بسبب مرض الطفل أو للتطعيم أو للحصول على نصيحة بشأن رعاية الطفل.

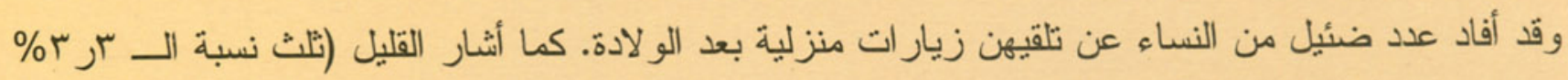
من النساء اللاتي عدن إلى العيادة للحصول على الرعاية الصحية بعد الو لادة) عن قبام مقدمى الخدمة الصحية بزيارتهن فى المنزل لمرة واحد بعد الو لادة. و الجدير بالذكر ان غالبية هذه الزيارات المنزلية ثمت من ثيلاثية إلى سبعة أيام بعد تاريخ الو لادة. كما تمت اغلب هذه الزيار ات المنزلية بو اسطة العاملات الصحيات.

المؤشر الثانسي : نسبة الأمهات اللاحي يقبلن استخد/م وسائل تنظيم الأسرة من بين الأمهات اللادي قصن بعدل

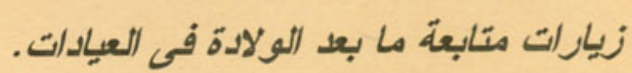

قبلت نسبة (حو الى 1§\%) استخدام وسيلة لتنظيم الأسرة من بين النساء اللاتى عدن لزيارة العيادة للحصول

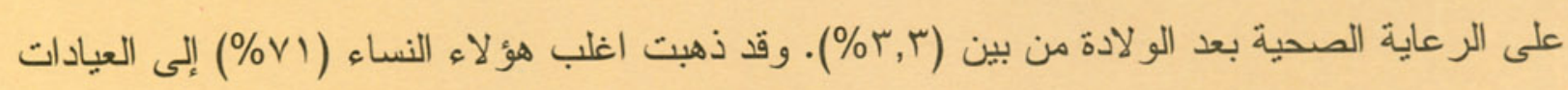
للحصول على وسيلة لتنظيم الأسرة بعد مرور فترة تنز اوح ما بين أربعة إلى ستة أسابيع من تاريخ الو لادة. ومع ذللك، فإن بعض النساء (1/\% من نسبة الــ بر ؟\% من النساء اللاتي عدن للحصول على الرعاية

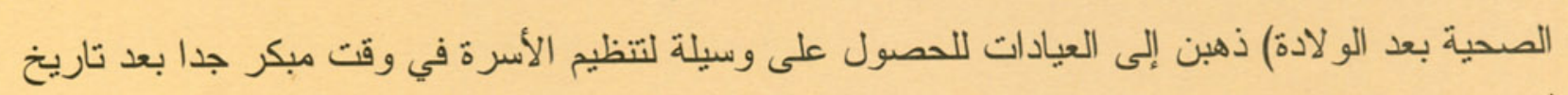


جدول ا : استخدام وسائل تنظيم الاسرة سابقا وحاليا

\begin{tabular}{|c|c|}
\hline$\%$ & \\
\hline טv & 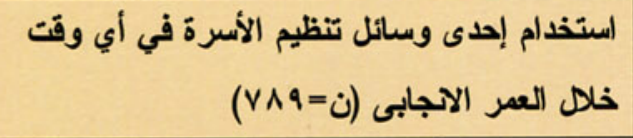 \\
\hline $01 \mathrm{j}$ & 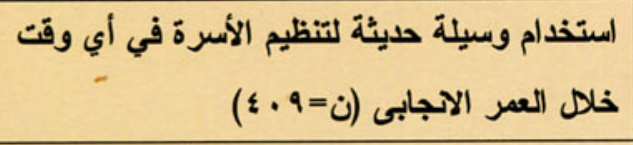 \\
\hline & 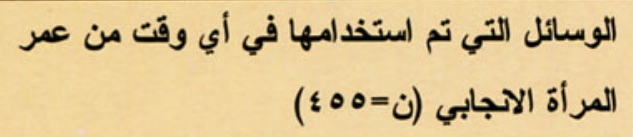 \\
\hline זر ד7 & اللولب \\
\hline أ & الحبوب \\
\hline IV & الو اقى الذكرى \\
\hline $7 \varepsilon$ & الحقن \\
\hline r & كبسو لات تحت الجلد \\
\hline ارץ & وسائل موضعية \\
\hline 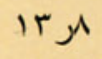 & القذف بالخارج \\
\hline rرr & الرضاعة الطبيعية \\
\hline r & فترة الأمان \\
\hline $1 \leqslant$ ر & 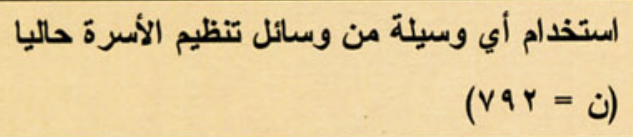 \\
\hline 9 & 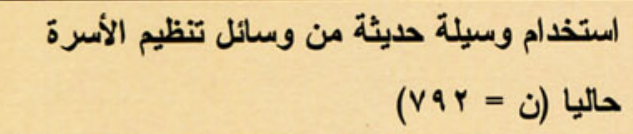 \\
\hline & وسائل تنظيم الاسرة المستخدمة (ن = \& I ا) \\
\hline Vار & اللولب \\
\hline זر & الحقن \\
\hline لر & الحبوب \\
\hline $1 \mathrm{j}$ & الو اقى الذكرى \\
\hline$\cdot{ }^{9}$ & وسائل أخرى \\
\hline rر & 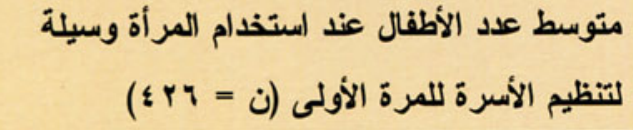 \\
\hline$r \leq ر$. & 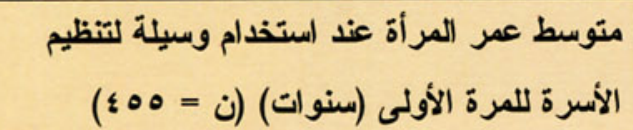 \\
\hline
\end{tabular}

الو لادة (قبل مرور ·× يوم من تاريخ الو لادة). وبالرغم من معرفة النساء عموما بوسائل تتظيم الأسرة

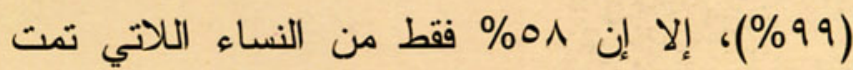
مقابلتهن استعملن في وقت من الأوقات إحدى هذه الوسائل. كما إن ع ا \% منهن فقط يستخدمن في الوقت الحالي إحدى وسائل تتظيم الأسرة (كما هو موضح فى

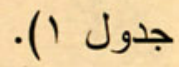

وقد أشارت نتائج الدراسة إلى أن اللولب هو اكثر وسائل تتظيم الأسرة انتشارا بين النساء اللاتي تمت

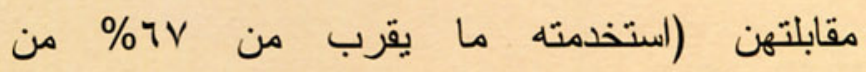
المستخدمات فى وقت من الأوقات) يليه الحبوب (استخدمته rع\%). وقد اتضح إن متوسط عمر النساء عند استخدامهن لوسيلة تتظيم الأسرة لأول مرة كان \& ع عاما. وكما هو موضتح فى جدول ا وجد إن

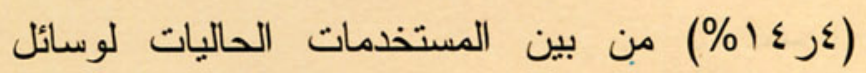
تتظيم الأسرة \% \% منهن يستخدمن اللولب، فى حين أن عدد اقل من النساء يستخدمن حاليا الحبوب (1) فقط) و الواقى الذكرى (r\% فقط من الأزواج). كما تستخدم r 1 من السيدات الحقن حاليا. وفي اغلب الحالات، تقوم النساء باختيار الوسيلة التي بستخدمنها

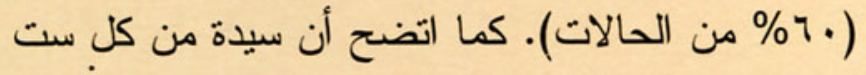
سيدات (1/1\%) أفادت أن زوجها كان له راب في اختيار وسيلة تتظيم الأسرة المستخدمة. وقد أثار عدد قليل من السيدات إلى أن مقدمي الخدمات الصحية هم الذين نصحوهن أو حفزوهن على اختيار وسيلة تتظيم الأسرة التي بستخدمنها في الوقت الحالي. 
المؤشر الثالث: نسبة النساء اللادي لديهن عدد قليل من الأطفال (طفل أو اثثين أحياء) ويقلبن استخدام إدىى

شكل ץ : متى بدأت استخدام وسيلة تنظيم الاسرة لأول مرة ؟

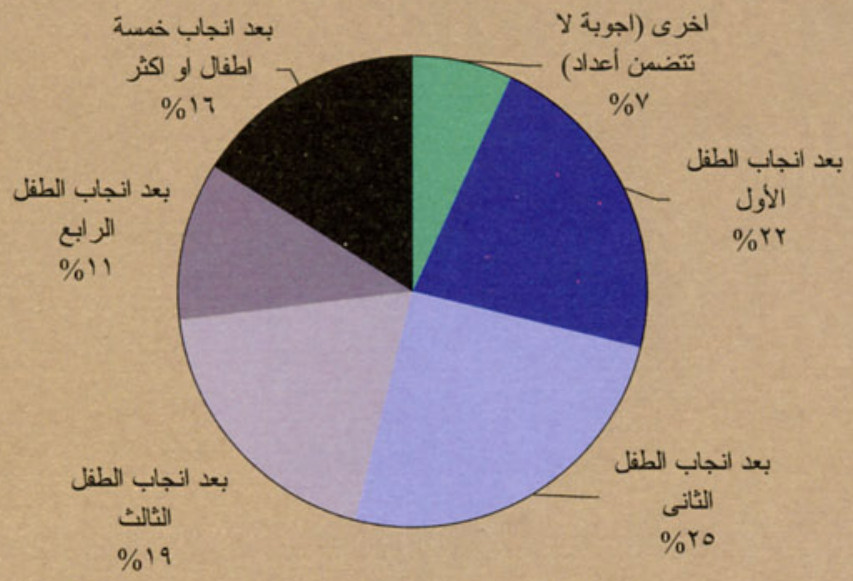

استذدام فى أى وقت خلا العمر الإجابى

وسائل تنظيم الأسرة.

بدأت النساء في استخدام وسائل تنظيم الأسرة عندما كان لديهن حوالي ثلاثة أطفال أحياء في المتوسط، ولا توجد سيدة واحدة أفادت عن استخدام وسائل منع ولع لوان الحمل لتأجيل إنجاب أول طفل. وقد سئلت النساء اللاتي سبق لهن استخدام وسائل نتظيم الأسرة عن عدد الأولاد عند استخدامهن وسيلة تنظيم الأسرة للمرة الأولى. حيث

اقر نصفهن تقريبا (V§\%) بأن عدد الأطفال كان طفلا أو طفلين. (شكل رقم r) وقد وجد أن بين النساء اللاتى تستخدمن حاليا وسيلة حديثة لتنظيم

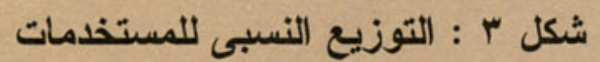

الحاليات لوسائل منع الحمل طبقا لعدد اطفالهم الاحبياء
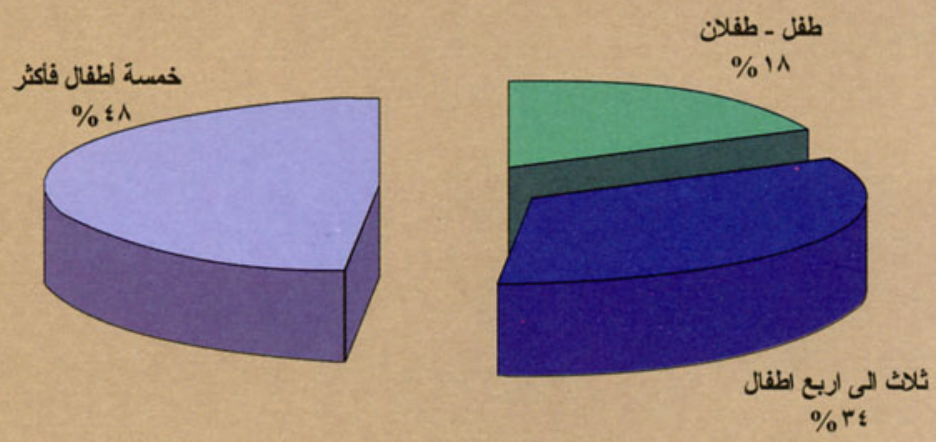

المصدر : مقابلات النساء بعد الحصول على الخدمة (ن= r + (1)
الأسرة (حوالى السدس) لديهن طفل

واحد أو اثثان أحياء، ولا توجد أبي سيدة تستخدم حاليا وسيلة لتأجيل إنجاب الطفل الأول (شكل رقم ؟).

المؤشر الرابع: زيادة معلومات الأمهات بعلامات الإنار لرئرة بالخطر خلا مرطة الحل ومرطة ما بعد الولادة بالنسبة لأنفسهن ولأطفالهن الرضع.

أشارت نتائج الدراسة إلى أن المعلومات والمشورة التي تلقتها النساء بشأن الرعاية الصحية أثناء الحمل و الرعاية الصحية بعد الو لادة وتنظيم الأسرة كانت غير كاملة ومنخفضة المسنوى. وقد تمكنت ما يقرب من

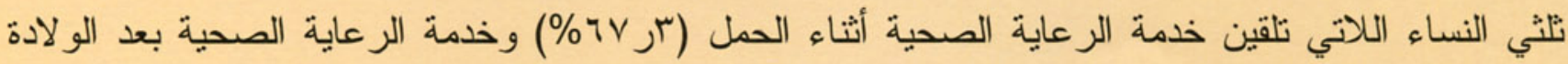


( (זر97\% من ذكر علامة أو علامنين على الأقل تتذران بالخطر . كما ذكرت جميع النساء اللاتي تلقين خدمة الرعاية الصحية بعد الو لادة علامة أو علامتين على الأقل تتذران بالخطر فيما يتعلق بصحة الوليد.

وقد أفاد ما بين نصف إلى تلثي النساء اللاتي تلقين خدمة الرعاية الصحية أثناء الحمل عن ثلقي معلومات متابعة نتعلق بثلاثة أو خمسة موضوعات تثصل بالرعاية الصحية أثناء الحمل. وبالرغم من ذلك، فقد أبلغت تلث النساء عن تلقي معلومات عن موضوع أو اثثين فقط ، كما أشارت خمس النساء إلى عدم تلقيهن أية معلومات على الإطلاق. وقد وجدت الدراسة أن السيدات اللاتى حصلن على خدمة ما بعد الو لادة قد تلقين

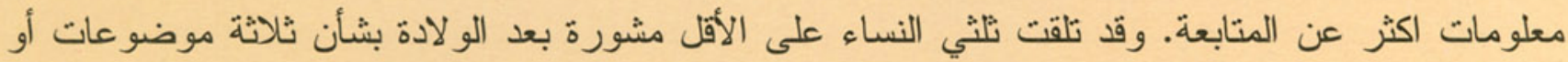
اكثر • ومن الملاحظ أن هذه النتائج تدل بصورة اكبر على وجود إدر الك اكثر من كونها تشير إلى وجود معرفة تقنية شاملة. وبالر غم من ذلك، فقد لوحظ أن تلث النساء اللاتى حصلن على الرعاية الصحية أثناء الحمل وبعد

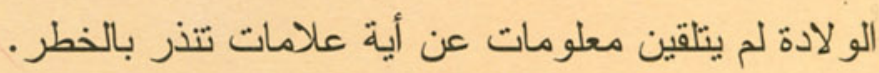

المؤشس الخامس: زيادة معلومات النساء عن سرطان الثدى وممارسة الفحص الذاتى للثدي واختبار مسحة عنق

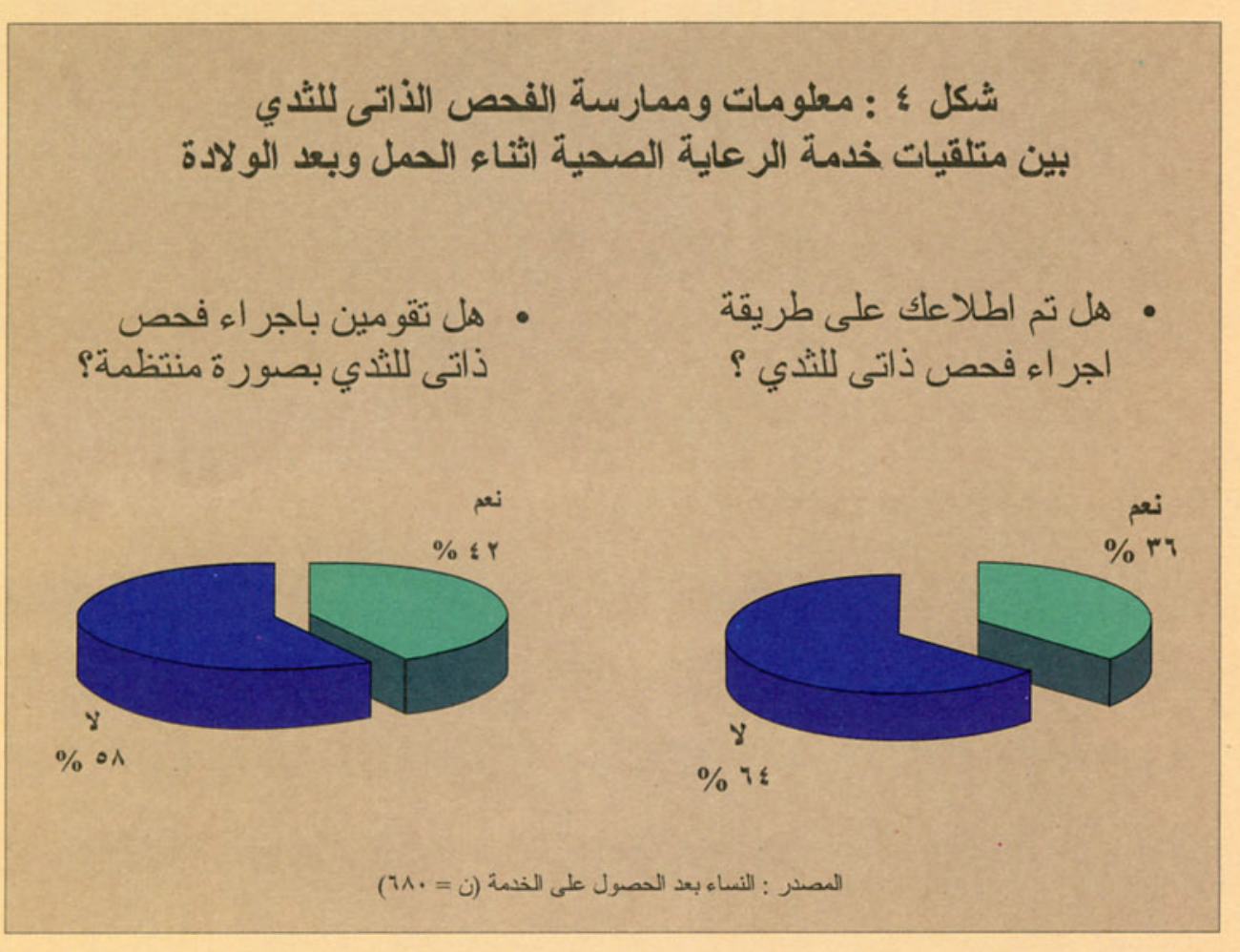

الرحم. (المبر

بالرغم من أن خدمات

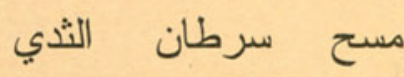
وسرطان عنق الرحم لا لان تشكل جزءا من الخدمات

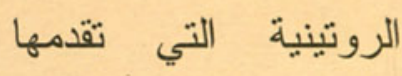
عيادات المشروع الصحي التجريبى، الا أن اقل من نصف الأطباء ابلغوا عن تنقيمهم مشورة روتينية عن كيفية إجر اء فحص ذاتى للثي إلى النساء اللاتي يتلقين خدمة الرعاية الصحية. كما أن اكثر بقليل من ثلث النساء الحوامل في فترة ما بعد الو لادة واللاتي تمت مقابلتهن ابلغن عن تلقيهن توجيهات أو استشارات عن كيفية إجر اء فحص ذاتى للثدي. و عندما سئلن عن المكان الذي نلقين فيه هذه المعلومات، أفاد ما يقرب من خمسهن 
(1\%) بأنهن تلقين المعلومات في نفس المركز الصحي الذي تمت مقابلتهن فيه، بينما أفادت اقل من ثلث النساء (1\%\%) عن تلقيهن تلك المعلومات فى مركز صحى أخر. كما صرحت نساء أخريات بأنهن تلقين المعلومات عن طريق الأصدقاء أو من خلال وسائل الإعلام. وبالرغم من تلقى معلومات عن كيفية إجر اء

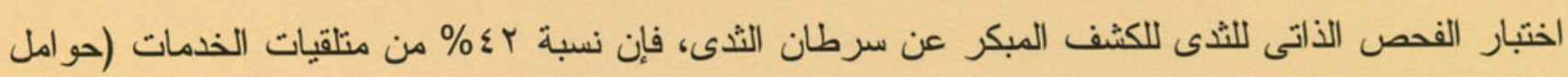
وبعد الو لادة) هن فقط اللاتي ابلغن عن إجر ائهن اختبارات الفحص الذاتى بانتظام (الثكل رقم ع).

كما ابلغ ما يقرب من نصف عدد الأطباء الذين تمت مقابلتهم بأنهم قدمو اخدمات اختبار مسحة عنق الرحم في عيادات المشروع الصحي التجريبى. وعند سؤال الأطباء، أفاد خمس المشاركون في الدراسة بأن

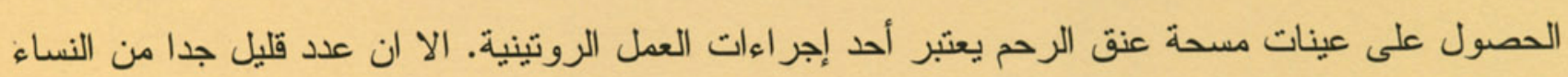

أفدن بإجر ائهن اختبار ات مسحة عنق الرحم في العيادات التي ذهبن اليها.

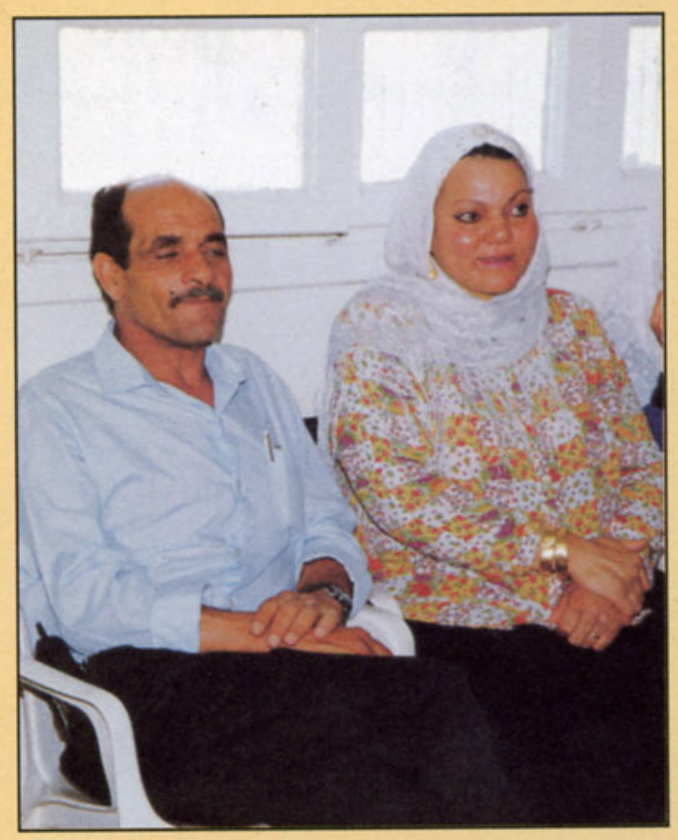

المؤشر السادس: زيادة نسبة الأزواج والرجال النين لليهم

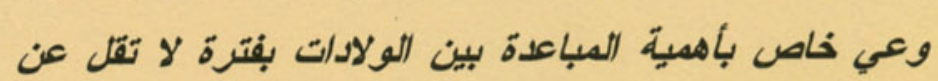

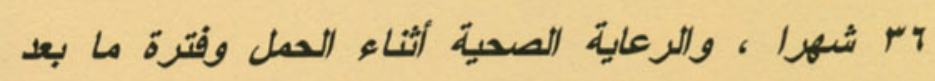
الولادة واستخد/م وسائل تنظيم الأسرة.

أفادت النساء بأن أزو اجهن - بوجه عام- يلعبو ا دور ا في الرعاية

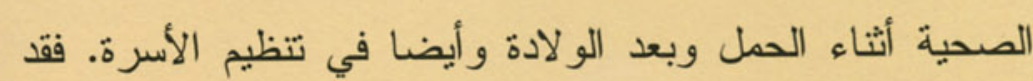

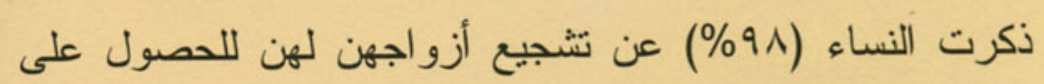

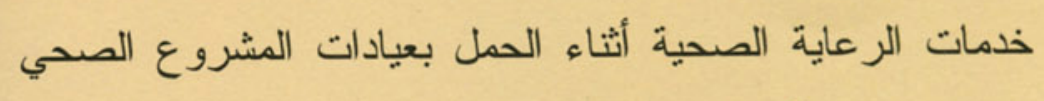
التجربيى، كما أبلغت نسبة مماتلة (97\%) أن أزو اجهن يعنقدن أن الرعاية الصحية أثناء الحمل هامة بالنسبة لصحة زوجاتهم. كما أن اغلب النساء اللاتي تلقين خدمة الرعاية الصحية أثناء الحمل (79\%) صرحن بمناقشتهن نتائج زيارات الرعاية الصحبة أثناء الحمل مع أزواجهن

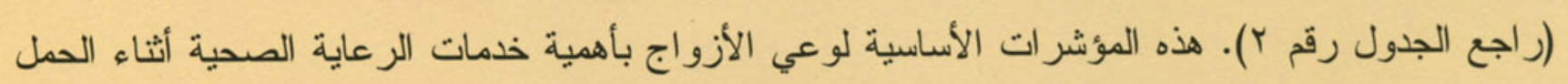
تعد عالية جدا. ومع ذللك، فإن مشاركة الأزواج (مثل مر افقة الزوجات عند الذهاب إلى العيادات للحصول

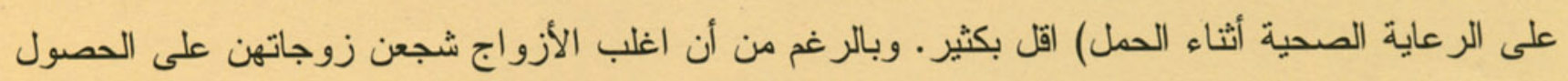

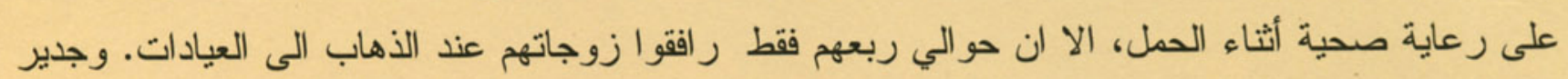
بالذكر انه عندما تم سؤالهن عما إذا كان الأزواج قد رافقوهن إلى العيادة في يوم المقابلة، أجابت نسبة . 
جدول r : إجابات النساء عن مشاركة أزواجهن

\begin{tabular}{|c|c|}
\hline 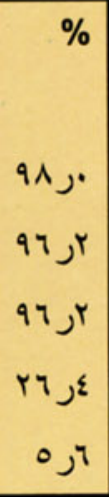 & 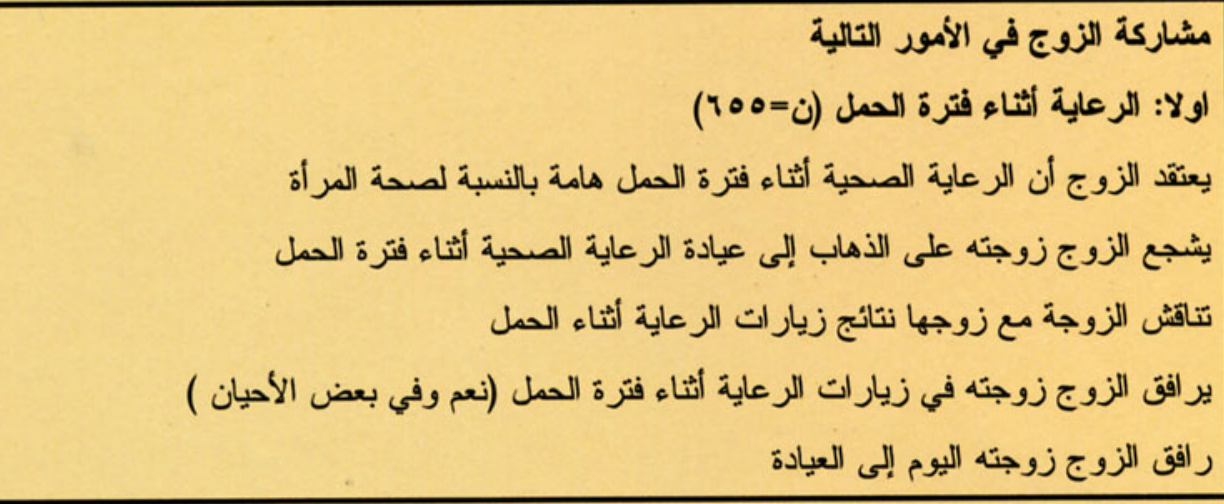 \\
\hline 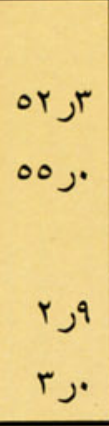 & 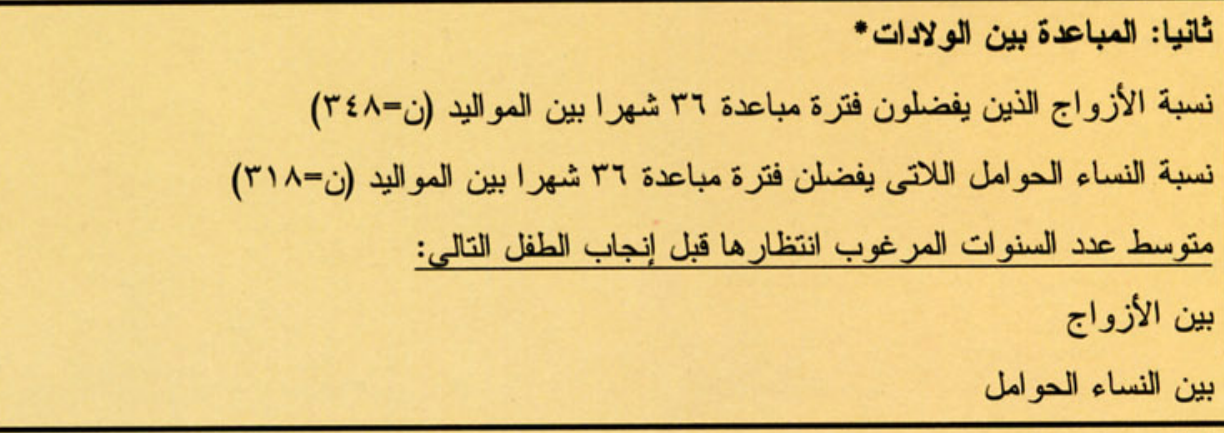 \\
\hline $\begin{array}{l}q 1 \text { هر } 9 \text { ه } \\
\text { ه }\end{array}$ & 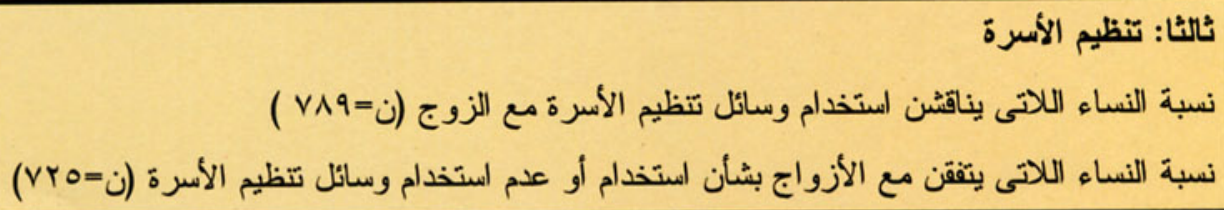 \\
\hline
\end{tabular}

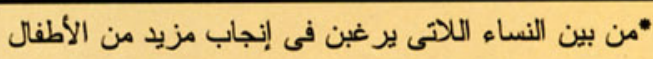

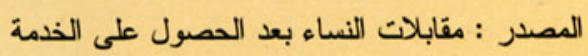

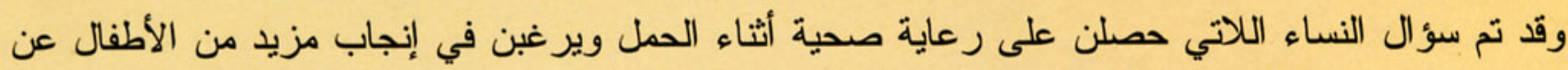
فترة الانتظار المفضلة لديهن بين هذا الحمل والو لادة التالية. كما تم سؤالهن عن فترة المباعدة بين الولادات

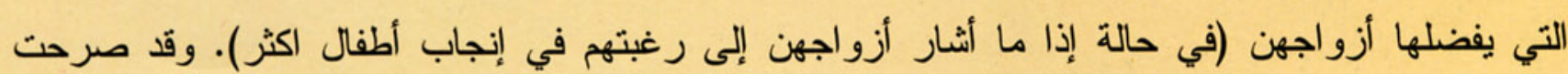
نصف النساء اللاتى تلقين خدمة الرعاية الصحية أثناء الحمل (00\%) بأنهن يفضلن الانتظار لمدة بس شهرا قبل الحمل التالي، كما تعتقد نسبة مساوية (r\%\%) أن أزواجهن يفضلون هم أيضا الانظظار لمدة بr شهر ا. (جدول r). كما أظهرت مقابلات ما بعد الحصول على الخدمة أن اغلب النساء ناقشن أزواجهن في موضوع استخدام وسائل تنظيم الأسرة. وقد أشارت كل النساء تقريبا (§9\%) إلى انه كان هناك تو اصلا مع أزو اجهن

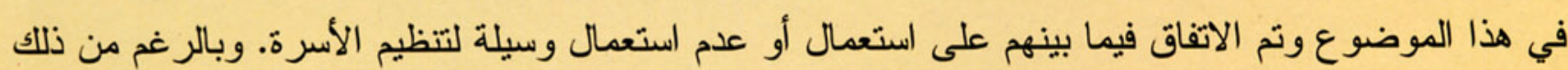

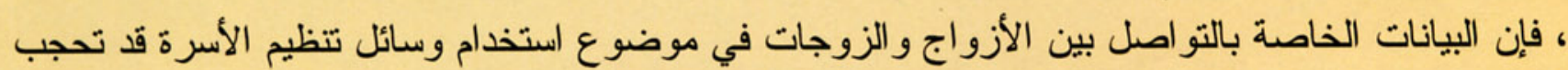
ديناميكية التفاوض بين الأزواج و الزوجات ، بما في ذلك قدرة الزوجات التفاوضية. 


\section{المؤشر السابع: زيادة المعلومات والمهارات للى جميع فئات مقدمي الخدمة الصحية}

تعد الزيارات المنزلية التي تقوم بها العاملات الصحيات أحد الأنشطة الأساسية للمشروع الصحي التجريبى، فموضوعات الرضاعة الطبيعية ورعاية الرضيع والحاجة لاستخدام إحدى وسائل تنظيم الأسرة والتغذية المناسبة يتكرر ذكرها كثير أثناء الزيارات المنزلية. وبالإضافة إلى التثقيف الصحي، ثقوم العاملات الصحيات بإجر اء بعض جو انب الفحص الطبى (الصدر و البطن و العجان) وقياس العلامات الحيوية، بالرغم

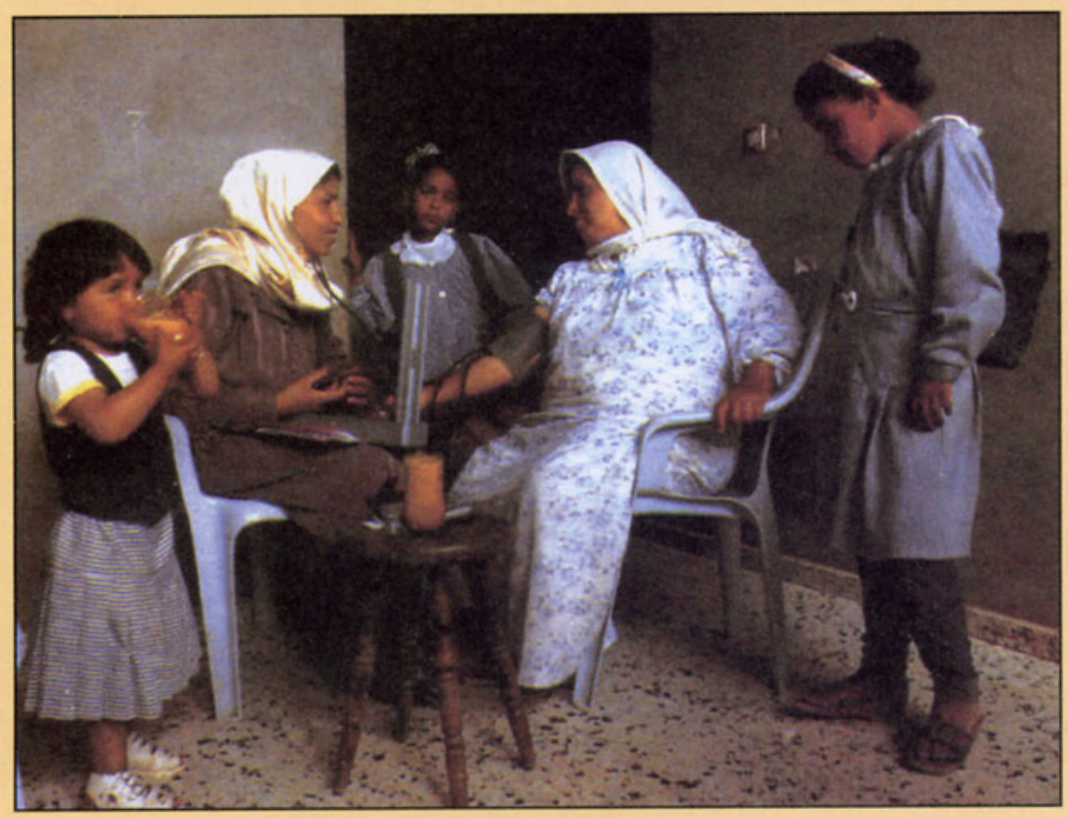

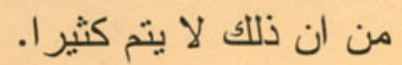

شجعت (\% ) من العاملات الصحبات والممرضات النساء على العودة إلى العيادة مرة أخرى خلال شهر من تاريخ الولادة لإجراء فحص ما بعد الولادة لهن وللفحص الطبى للرضيع (ع^\%). كما و وجد أن المسنتى الأساسي للمطلومات عن علامات الإنذار بالخطر خلال فترة الحمل مرتفع. فقد كان جميع الأطباء قادرون على الإبلاغ عن خمسة عو امل من بين r ا عاملا تتعلق بعلامات الإنذار . ويقل نسبيا ذكر عو امل علامات الإنذار الخاصة بفترة ما بعد الولادة و المو اليد الجدد على الرغم من انها ماز الت عالية. فقد استطاع غالبية الأطباء (^^\%) ذكر 0 عو امل من بين 17 عامل نتعلق بسجل التوليد الذي يجب سؤال النساء

أخير ا، فقد كان هناك خلاف بين الأطباء بشأن الحد الأدنى لعدد زيارات الرعاية الصحية أثناء فترة الحمل

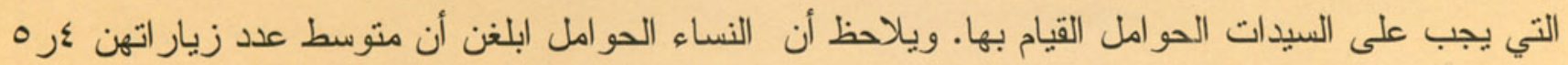

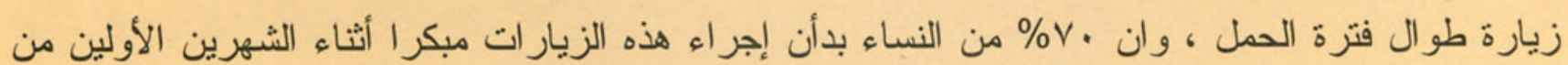

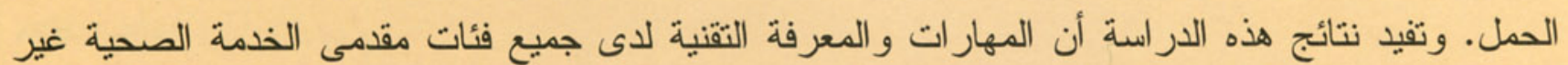
كافية. وبالر غم من أن ما يقرب من ثلاثة أخماس العاملات الصحيات (عددهن الكلى r أ) ابلغن عن حصولهن على دبلوم أو تلقيهن تدريبات، الا ان المستوى الإجمالي للتعليم و التذريب لدى جميع فئات مقدمى الخدمة غير 
موحد، وليس على المسنوى القياسى. وفي الواقع، فقد أثار اغلب الأطباء عن حاجتهم لتلقي تدريبات إضافية في مجال صحة المر أة.

المؤشر الثامن : تزويد النساء الحوامل والنساء خلا فترة النفاس بعطلومات عن التغنية والنظافة والرضاعة

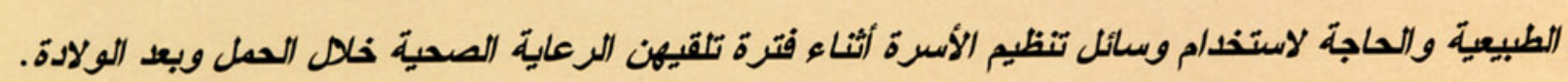

تم سؤال النساء اللاتي تلقين رعاية صحية أثثاء الحمل أو بعد الولادة عن المعلومات التي تلقينها من مقدمي

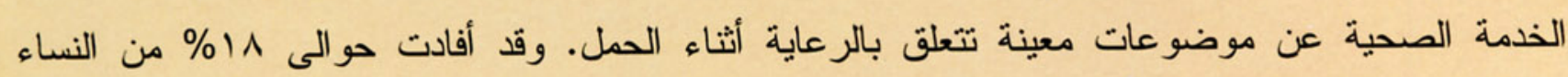

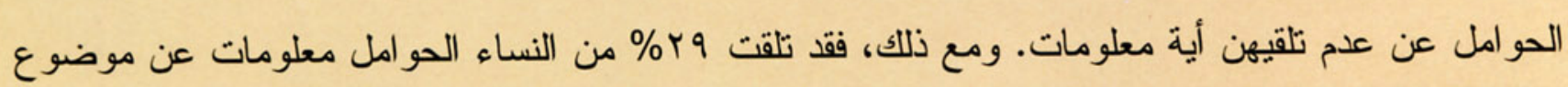

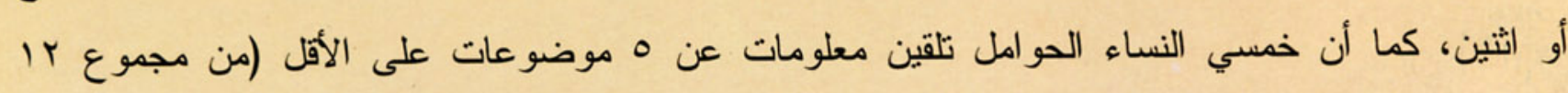

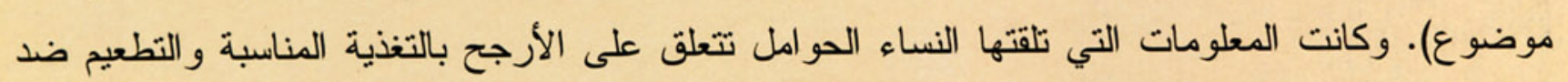

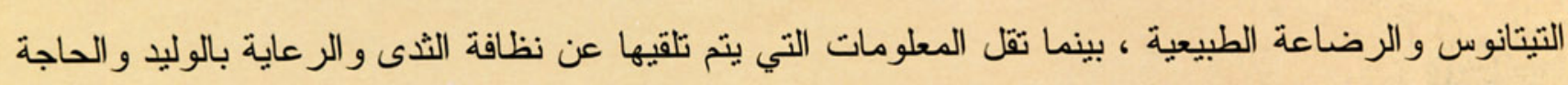
لاستخدام وسيلة تتظيم الأسرة بعد انتهاء فترة الحمل.

وقد أبلغت معظم النساء في فترة النفاس عن تلقيهن معلومات عن موضوعات قليلة تتعلق بالرعاية الصحية

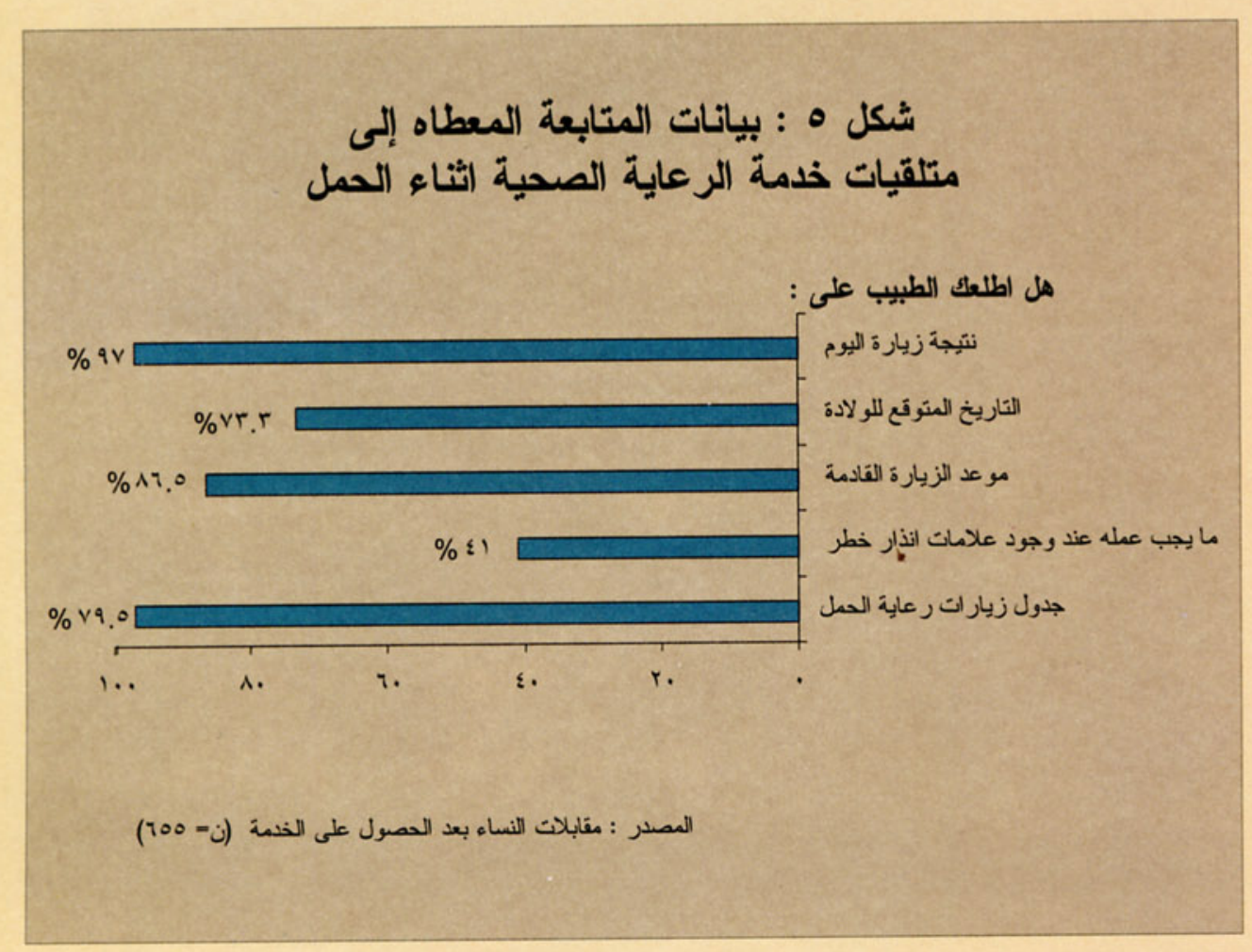

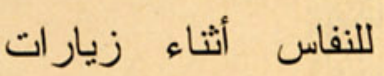
النفاس. الا ان حوالي سدس النساء ذكرن عدم تلقيهن أية معلومات عن موضوعات الرعاية الصحية أثناء النفاس، كما أثارت نسبة الربع إلى تلقيهن معلومات عن ثلاثة أو أربعة موضوعات وما يقرب من خمسي النساء تلقين معلومات عن خمسة موضوعات على الأقل (من بين 9 موضوعات). وتحصل النساء أثثاء النفاس في الأرجح على معلومات عن 
الرضاعة الطبيعية ورعاية الوليد وجذول التطعيم وتتظيم الأسرة. ولكن، تقل احتمالات تلقيهن معلومات عن التمارين الرياضية الخاصة بفترة النفاس و النظافة الشخصية و التغذية المناسبة.

كما أن ما يقرب من خمسي النساء اللاتى تلقين رعاية صحية أثناء الحمل نم اطلاعهن على الإجراء الواجب القيام به عند إحساسهن بأية علامات إنذار بالخطر تتعلق بالحمل الحالى (شكل رقم 0). كما نم إبلاغ ما بين r \% \% إلى Vq \% من النساء عن الثاريخ المتوقع للولادة وجدول زيارات رعاية الحمل وموعد الزيارة القادمة ونتائج زيار اتهن وذلك في يوم إجر اء مقابلتهن بعد الانتهاء من تقديم الخدمة.

عند سؤال النساء عما إذا كن قد حصلن على أية وسائل لتتظيم الأسرة من العيادة التي تمت فيها مقابلتهن،

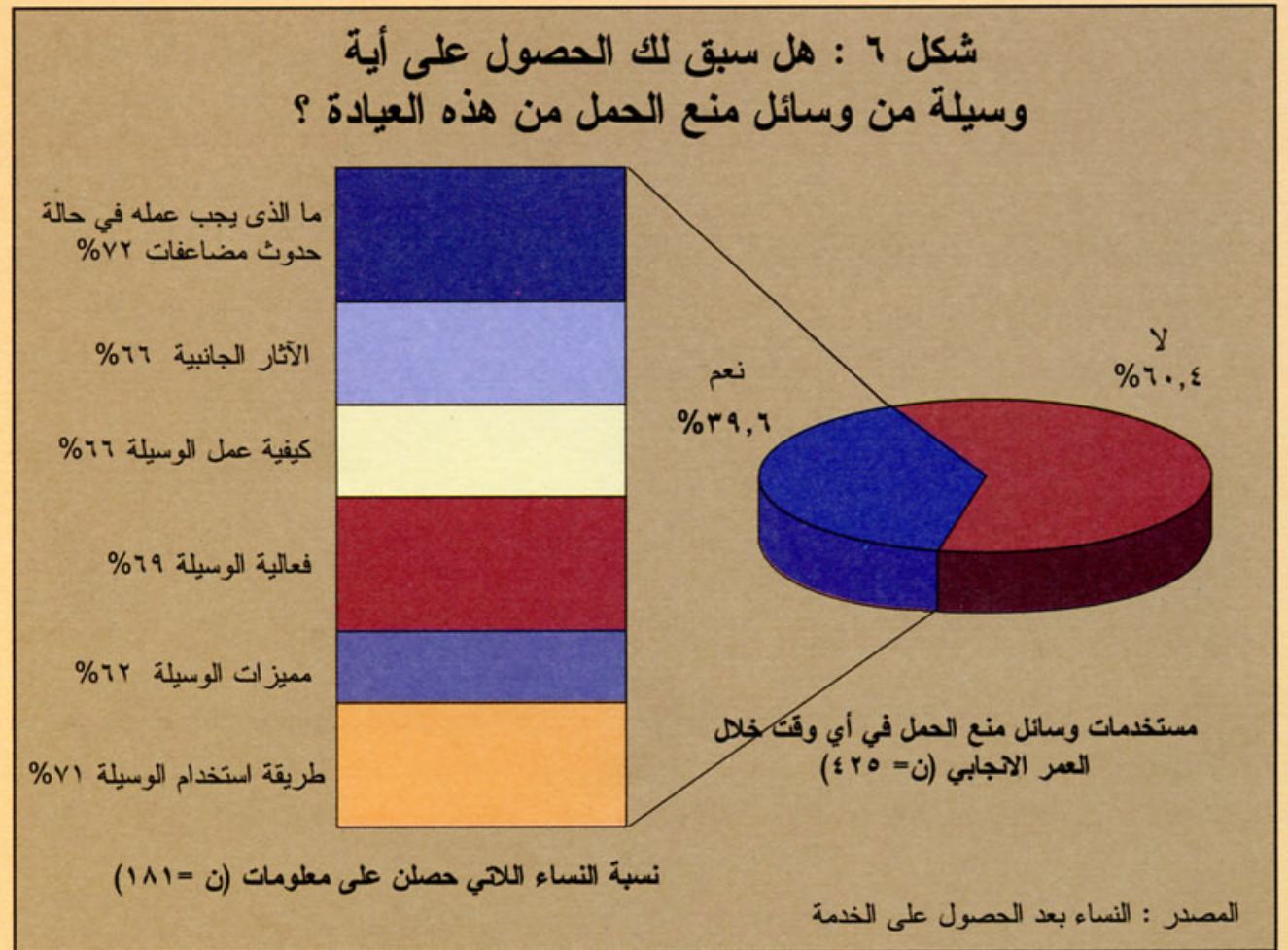

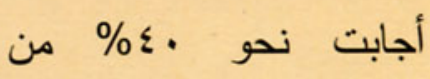
النساء الاتي استخدمن إحدى الوسائل بــــ "نعم" (شكل ب ال). وقد ثم سؤال هؤلاء النساء عن نوعية المعلومات التي حلن عليها عند استلام وسيلة لتتظيم الأسرة، فأجابت ثلثى النساء بأنهن تلقين معلومات أساسية عن الوسيلة التي حصلن عليها تتضمن كيفية عمل الوسيلة في منع حدوث الحمل وطريقة الاستخدام وفعاليتها ومميز اتها وتأثير اتها الجانبية وما يجب عمله في حالة حدوث شكوى ناتجة عن استخدام هذه الوسيلة.

وبالرغم من النتائج المذكورة أعلاه، فلا تز ال هناك إمكانية لتطوير وتحسين عملية توصيل المعلومات المتعلقة بتنظيم الأسرة، فالنساء بحاجة إلى تلقي معلومات اكثر عن الأنواع المختلفة من الوسائل المتاحة، وثوفير المشورة الطبية لجميع النساء اللاتي يذهبن إلى عيادات المشروع الصحي التجريبى لاسيما وان ما يقرب من تلث النساء قد ابلغن عن عدم تلقيهن أية معلومات عن تتظيم الأسرة. 


\section{معلومات إضافية عن الخدمات التي تقدمرا عيادات المشروع الصحى التجريبى إصافي عن}

تتيح الدر اسة فرصة التعرف على جودة خدمات رعاية الأمومة والطفولة وسهولة الوصول إلى هذه الخدمات

جدول r : بعض المؤشرات المختارة عن سهولة الوصول إلى عيادات المشروع الصحي التجريبى

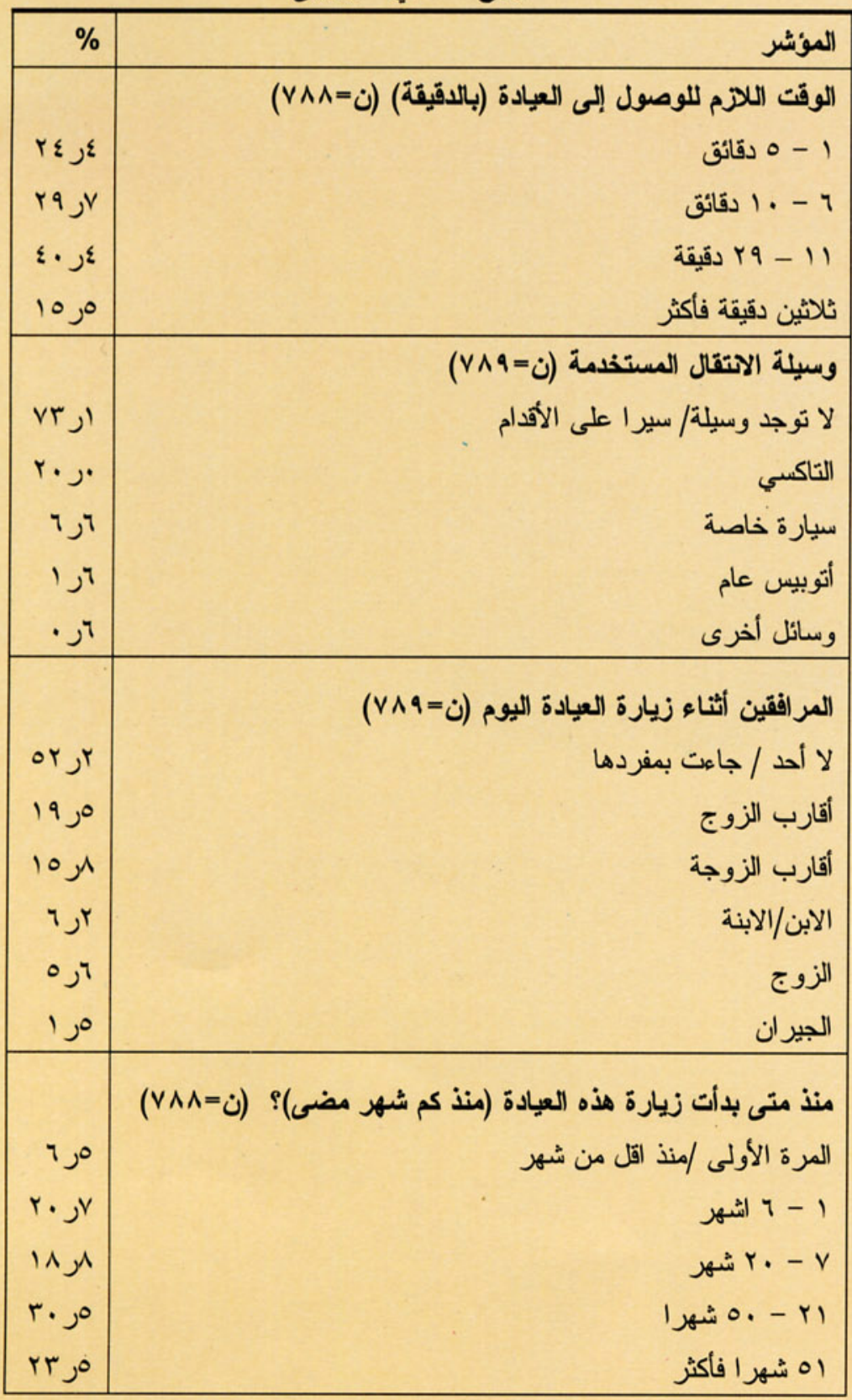
بالإضافة إلى جمع البيانات التي تقيس مستوى المؤشرات الأساسية لمخرجات المشروع الصحي التجريبى.

جودة الرعابة

تشير النتائج إلى أن غالبية كبيرة من النساء اللاتي يذهبن للحصول على خدمات الرعاية الصحية في عيادات المشروع الصحي التجريبى بشعرن بجودة البيئة المحيطة وبلطف واحتر ام الموظفين العاملين بالعيادة. كما أبدين تقديرهن للخصوصية التي تلقينها أثناء الفحوص، و الوقت الذي. منح لهن لسؤال مقدمي الخدمة والترحيب الحار بهن عند دخولهن للعيادة (حسبما أفادت ب9 \% إلى \%^\% من النساء). كما أن اغلب النساء أفدن بأنه تم اجلاسهن في صالة الانتظار وشعرن بالر احة أثناء هذه الفترة (79 \% و \& \% على التوالي). وقد انعكست هذه النتائج على تقييم مستويات الرعاية في عيادات المشروع الصحي التجريبى التي نم إجرائها عام 1999 (يونس وحسنين

999 ( 99 '. ومع ذلك، فأنه تجدر ملاحظة أن بعض النساء كانت لديهن انطباعات سلبية عن مساحة العيادة ، حيث أجابت نسبة ٪1^\% بالإيجاب على سؤال "هل كانت العيادة فسيحة؟". 
كما نم سؤال النساء عن أسباب تفضيل العيادات التى يزرنها ، وكان اكثر الأسباب ذكرا (^^\%) قرب العيادة إلى المنزل. كما شملت هذه الأسباب الثقة في الأطباء (حوالي بr؟\%)، وجودة الرعاية بالمقارنة بالعيادات

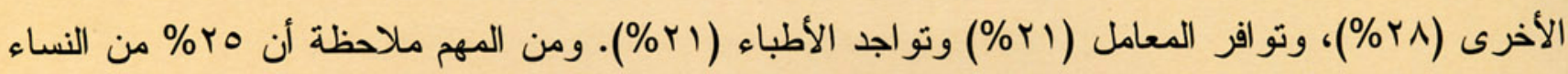
ذكرن رخص نكلفة الخدمات كأحد أسباب زيارة بعض العيادات. كما أشارت أيضا نسبة 7 ا \% من النساء بأنه لم يكن لديهن خيار أخر وان العيادات التي زرنها كانت هى الوحيدة المتاحة أمامهن.

\section{سهولة الوصول إلى خدمات الرعاية الصحية}

تعكس نتائج الدراسة مستويات مرتفعة من سهولة الوصول إلى عيادات المشروع الصحي التجريبى. حيث

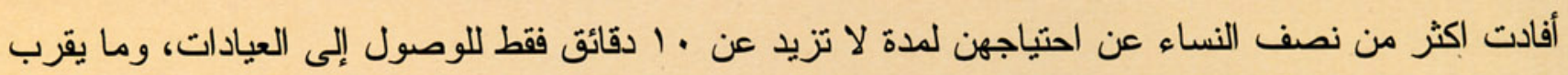
من ثلاثة أرباع النساء أفدن بأنهن يذهبن إلى العيادة سيرا على الأقدام ولا يحتجن إلى استخدام أية وسيلة

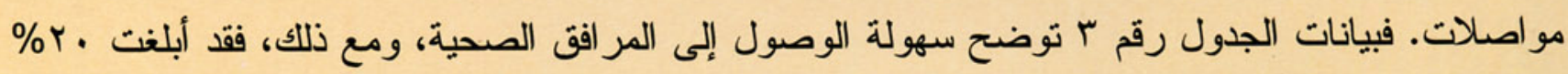
من النساء عن ذهابهن إلى العيادات باستخدام سيارات الأجرة.

وعند سؤال النساء عن الأشخاص الذين رافقوهن إلى العيادات، أفادت ما يقرب من نصفهن بذهابهن وحدهن

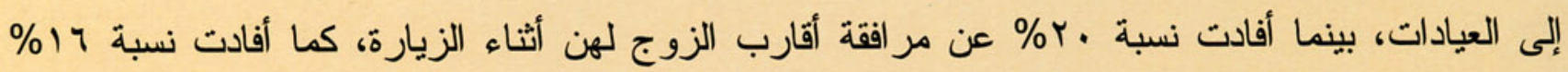
بمر افقة أقارب لهن أثناء الزيارة. وقد أفادت ما يقرب من نصف النساء بزيارة العيادات خلا العشرين شهرا

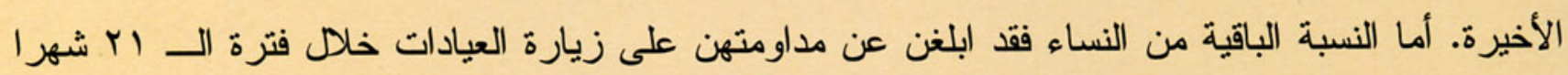

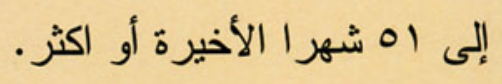

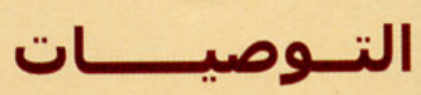

بناء على النتائج المذكورة أعلاه، نوصي باتباع الخطوات التالية على صعيد السياسات و البر امج بهدف تأسيس وترسيخ نوعية ممتازة من خدمات الرعاية الصحية أثناء الحمل وبعد الو لادة:

التطبيق العاجل لمقاييس البروتوكول الوطنى والإرشادات المطورة حديثا الخاصة بالرعاية الصحية أثناء الحمل وبعد الو لادة ، بما في ذلك تنظيم الأسرة ومسح سرطان الثدي وسرطان عنق الرحم في عيادات ومر اكز الرعاية الصحية الأولية. 
التأكيد على توفير تدريبات إضافية لجميع فئات مقدمى الذدمات الصحية وذلك فيما يتعلق بالرعاية

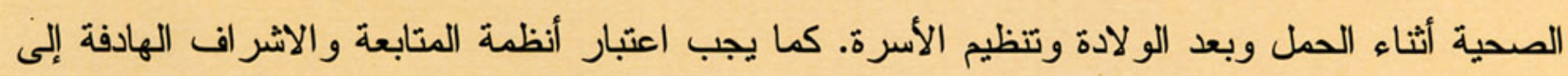
ضمان استدامة أنشطة التدريب جزءا أساسيا في جميع بر امج التدريب. تأسيس آليات الإحالة بين المستشفيات ومر اكز وعيادات الرعاية الصحية الأولية لضمان حصول المرأة على الرعاية الأساسية خلال فترة ما بعد الولادة. زيادة عدد ساعات التدريب المخصصة لصحة المر أة بكليات الطب وبر امج التدريب.

توعية الجمهور وتوفير مزيد من المطلومات عن أهمية الرعاية الصحية أثناء الحمل وبعد الولادة بما فى

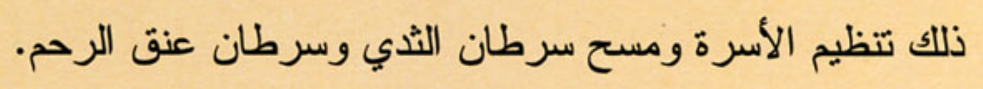

تحسين الخدمات الميدانية لتتبع والوصول الى السيدات اللاتي إنقطعن عن الذهاب إلى زيارات الرعاية الصحية أثثاء الحمل أو اللاتي ليست لديهن نية الحصول على الرعاية الصحية بعد الولادة.

إدخال ضمان الجودة والإدارة الجيدة ضمن مجموعة الخدمات الشاملة التي تقدمها عيادات الرعاية الصحية الأولية. 
USAID تم تثفيذ هذا المشروع بدعم من الوكالة الأمريكية للتنمية الدولية ، مكتب الصحة والسكان ، فى ظل اتفاق

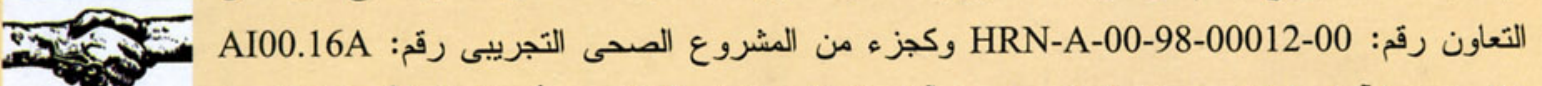

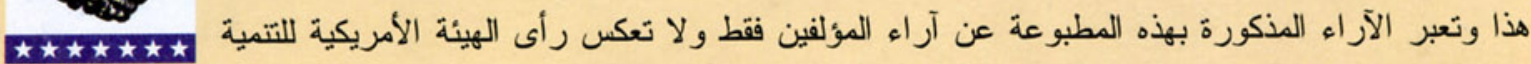

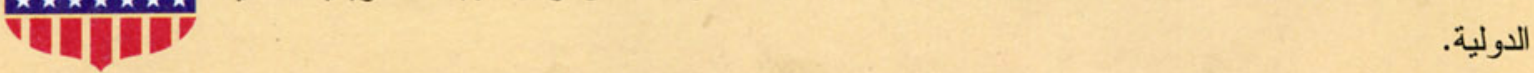

